\title{
Cytoplasmic domains and voltage-dependent potassium channel gating
}

\section{Francisco Barros*, Pedro Domínguez and Pilar de la Peña}

Departamento de Bioquímica y Biología Molecular, Universidad de Oviedo, Oviedo, Asturias, Spain

\section{Edited by:}

Gildas Loussouarn, University of Nantes, France

\section{Reviewed by:}

Bernard Attali, Tel Aviv University, Israel

Martin Tristani, University of Utah, USA

\section{*Correspondence:}

Francisco Barros, Departamento de Bioquímica y Biología Molecular, Universidad de Oviedo, Edificio Santiago Gascón, Campus del Cristo, 33006 Oviedo, Asturias, Spain. e-mail: fbarros@uniovi.es

\begin{abstract}
The basic architecture of the voltage-dependent $\mathrm{K}^{+}$channels ( $\mathrm{Kv}$ channels) corresponds to a transmembrane protein core in which the permeation pore, the voltage-sensing components and the gating machinery (cytoplasmic facing gate and sensor-gate coupler) reside. Usually, large protein tails are attached to this core, hanging toward the inside of the cell. These cytoplasmic regions are essential for normal channel function and, due to their accessibility to the cytoplasmic environment, constitute obvious targets for cell-physiological control of channel behavior. Here we review the present knowledge about the molecular organization of these intracellular channel regions and their role in both setting and controlling Kv voltage-dependent gating properties. This includes the influence that they exert on $\mathrm{Kv}$ rapid/N-type inactivation and on activation/deactivation gating of Shaker-like and eag-type Kv channels. Some illustrative examples about the relevance of these cytoplasmic domains determining the possibilities for modulation of Kv channel gating by cellular components are also considered.
\end{abstract}

Keywords: potassium channel, voltage-dependent gating, cytoplasmic domains, structure-function relationships, inactivation gating, activation/deactivation gating
Ion channels are integral membrane proteins allowing for the passive passage of specific inorganic ions across cell membranes, propelled by their electrochemical gradients. Voltage-dependent or voltage-gated channels are proteins in which some parts of the molecule change their conformation in response to alterations of the electric field within the membrane (i.e., the transmembrane voltage), shifting the conformational equilibrium back and forth from closed to open (and inactivated) states (Figure 1; for an overview see Hille, 1992; Coetze et al., 1999; Swartz, 2004, 2008; Yu et al., 2005; Ashcroft, 2006; Bezanilla, 2008). Inactivation is a process by which an open channel enters a stable non-conducting state after a maintained depolarizing change in membrane potential.

Voltage-dependent potassium channels (Kv channels; Gutman et al., 2005) belong to a family of proteins (Figure 2) characterized by the presence of a pore-forming subunit with a six transmembrane segment (S1-S6) topology in which the last two segments, linked by a pore loop, constitute the ion-permeation pore. The voltage-sensing domain is formed by the S1-S4 segments, in which S4 contains a high density of positively charged residues and is the main transmembrane voltage-sensing component (Yellen, 1998, 2002; Swartz, 2004, 2008; Yu et al., 2005; Ashcroft, 2006; Bezanilla, 2008). Aside from the possible presence of accessory subunits (see below), in the Kv channels four pore subunits form a tetrameric structure surrounding a central conduction pathway (Figure 2). This oligomeric organization is also shared by other members of the family (not all of them activated by voltage) including cyclic nucleotide-activated channels, hyperpolarizationactivated cation channels, $\mathrm{Ca}^{2+}$-activated $\mathrm{K}^{+}$channels, and TRP channels. Voltage-gated $\mathrm{Ca}^{2+}$ and $\mathrm{Na}^{+}$channels share this overall organization, but instead contain four similar repeats with six transmembrane segments in a single polypeptide, mimicking the Kv tetramers (Yellen, 1998, 2002; Swartz, 2004, 2008; Yu et al., 2005; Ashcroft, 2006; Bezanilla, 2008).

At least three functional elements are found in the Kv channels: an ion conduction pore in which the ionic selectivity resides, a voltage sensor that detects changes in the electric transmembrane field, subsequently coupling its conformational states to the operation of the gate(s) (i.e., to channel gating), and one or more gates that open and close in response to voltage. Three possible gates have been recognized in Kv channels (Yellen, 1998, 2002): (i) an activation gate located at the cytoplasmic face of the permeation pore at the end of the S6 transmembrane helix, (ii) a pore or selectivity filter gate at the level of the selectivity filter itself, and (iii) an inactivation gate capable of plugging the pore from the cytoplasmic face. The first two gating mechanisms are linked to conformational rearrangements of the voltage sensors, providing the activation and C-type inactivation properties to the $\mathrm{Kv}$ channels, and the third mechanism confers the rapid/N-type inactivation behavior (Figure 1).

Selectivity filters, voltage sensors, and most gating elements of the $\mathrm{Kv}$ channels are located within the transmembranal portion of the channel core, except for the cytoplasmic gates themselves and the sensor-gate coupler(s) (e.g., the S4-S5 linker) that are located at the cytoplasmic channel surface and therefore can also be considered cytoplasmic (Figure 2). Whereas this basic architecture pertains to the whole voltage-dependent cation channel superfamily, additional elements exist in the form of intracellular domains and/or accessory subunits, able to strongly influence the gating properties (Minor, 2001; Varshney and Mathew, 2003; Roosild et al., 2004) and thus regulate channel functionality, either directly or in response to exogenous modulators. The contribution 


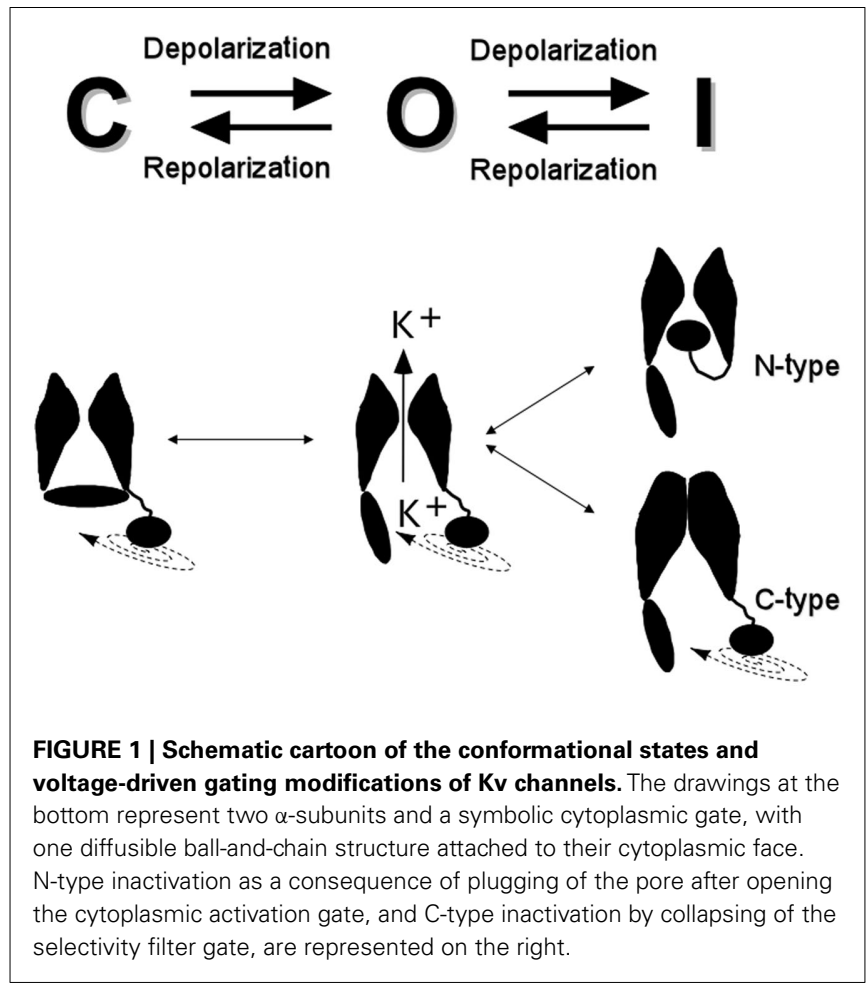

of additional accessory $\beta$-subunits to channel behavior (reviewed in Li et al., 2006; Bett and Rasmusson, 2008; Pongs and Schwarz, 2010; Vacher and Trimmer, 2011) will not be considered here. In order to review the current knowledge about the participation of cytoplasmic structures in the gating behavior of $\mathrm{Kv}$ channels, we will consider first the structural organization of these channel domains. Then, using well studied examples (e.g., Shaker-like and eag channels), we will focus on the role of cytoplasmic regions in determining channel gating properties. Recent data about the interactions between the $\mathrm{N}$ - and $\mathrm{C}$-terminal cytoplasmic regions and/or between them and components of the gating machinery in the channel core (e.g., the S4-S5 linker or the gate) will also be considered. Finally, we will review some cases illustrating the modulation of gating properties through signal transduction elements such as calmodulin or protein kinases and/or phosphatases.

\section{STRUCTURAL ORGANIZATION OF THE Kv CHANNEL CYTOPLASMIC DOMAINS}

The tridimensional structure of the transmembrane core of some Kv channels has been solved at high resolution (Jian et al., 2003; Long et al., 2005a, 2007). Given the overall identity and primary structure conservation of these protein segments, it is reasonable to assume that all of the Kv family members would share a common arrangement in these regions. However, solving the high-resolution structure of a complete $\mathrm{Kv}$ channel still remains a major challenge and the tridimensional structure and/or complete architecture of the cytoplasmic domains of the $\mathrm{Kv}$ channels are unknown. In fact, these regions show far more divergence than the rest of the molecule does, even among closely related channels. Nevertheless, specific regions of these domains have been structurally characterized using a "divide and conquer" approach

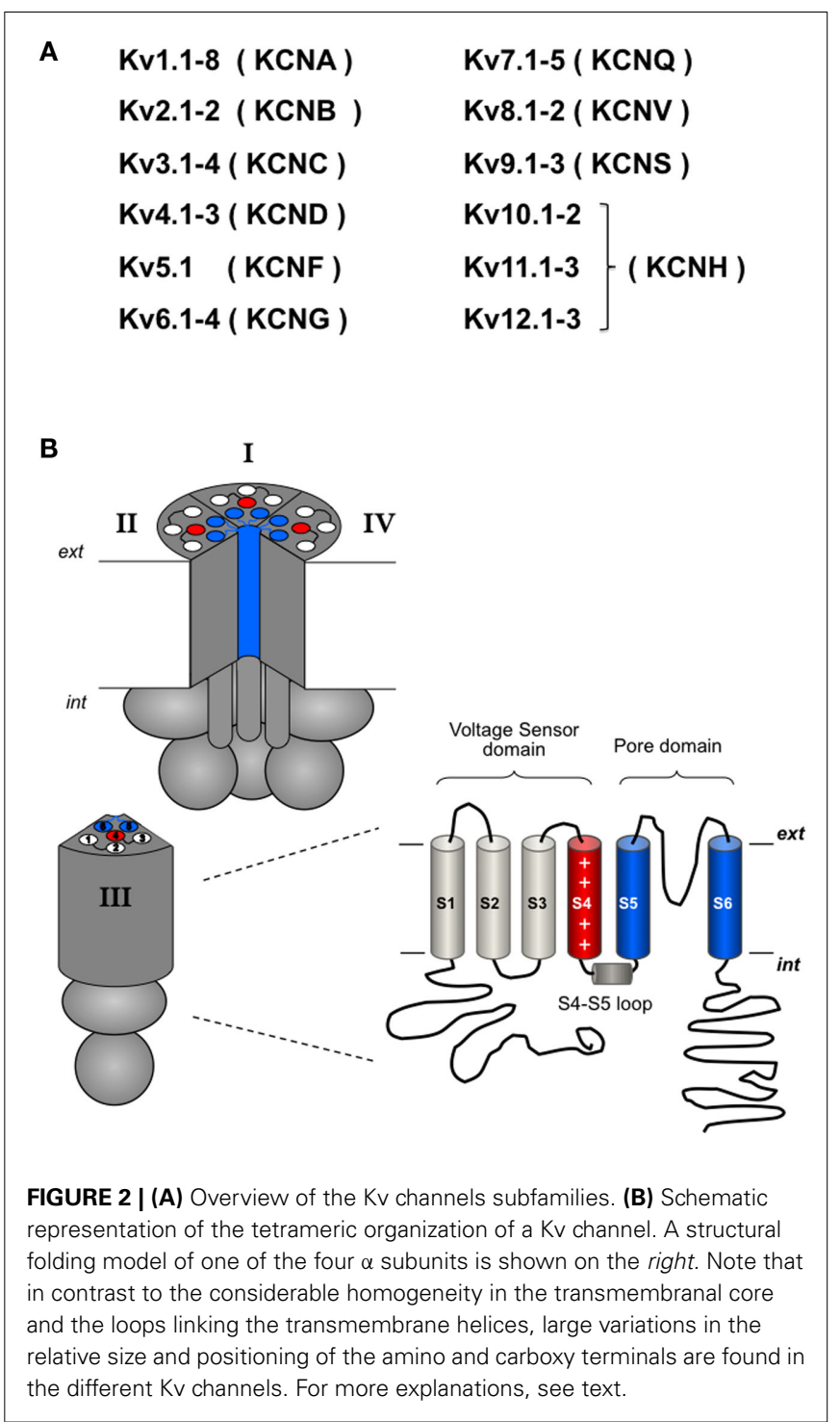

(Gaudet, 2009), thus providing partial information to be joined together and integrated with biochemical and electrophysiological data to yield a better picture of the channel organization on a domain by domain basis (Biggin et al., 2000). This approach has led to the proposal of two general assemblies for the Kv channel cytoplasmic components (Figure 3; Yellen, 2002): (a) The pattern typically exhibited by the Kv1-Kv4 cluster (Yu et al., 2005; Pischalnikova and Sokolova, 2009), in which, hanging centrally below the transmembranal core there is an N-terminal T1 "tetramerization domain" that determines, among other functional characteristics, the specificity of subunit assembly. (b) The pattern shared by the Kv7 and Kv10-Kv12 channels, characterized by the absence of a $\mathrm{T} 1$ domain and the presence of a C-terminal domain located centrally below the transmembrane channel core. Interestingly, this second overall organization also pertains to other relatives from the voltage-gated ion channel superfamily (Gutman et al., 2005; Yu et al., 2005), including those gated coordinately by voltage and ligand binding [such as the hyperpolarization-activated and cyclic 


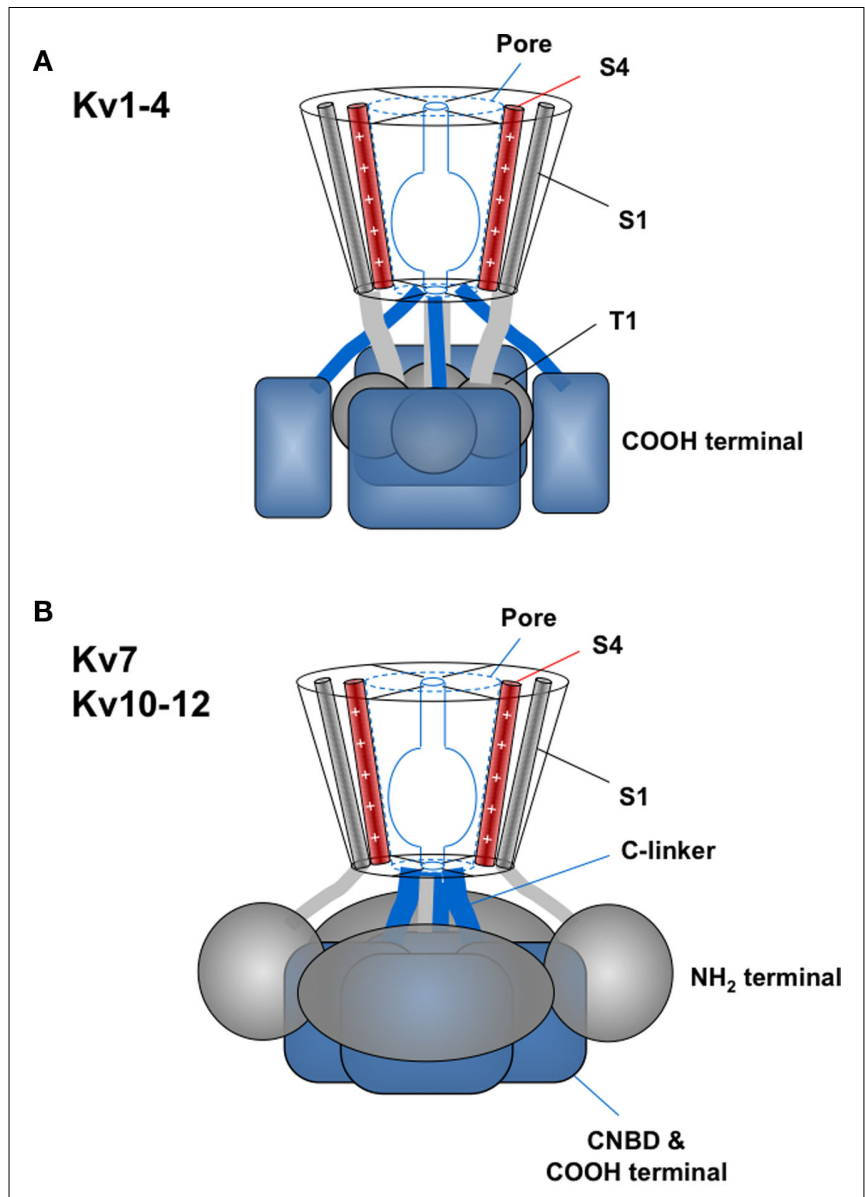

FIGURE 3 | Basic patterns of Kv channel cytoplasmic domains structural organization. (A) General organization of the Kv1-Kv4 channels group with the T1 "tetramerization domains" hanging centrally below the transmembranal core and attached to it through four linkers continued from the first transmembrane helices. In this case the C-terminal structures probably track to the periphery surrounding T1 and extending to its bottom. (B) General cytoplasmic architecture of the Kv7 and Kv10-Kv12 channels characterized by a carboxy terminus (i.e., the $\mathrm{C}$-linker/CNBD region of the Kv10-Kv12 channels or the A-D helical regions of the Kv7 channels) forming a compact tetrameric structure in a central position immediately below the cytoplasmic pore opening. In this case the amino terminus probably surrounds the C-terminus and extends to its bottom establishing extensive contacts with its top and side surfaces. Note that in both models the initial amino terminal structures (ball-like and eag/PAS domains for Kv1-Kv4 and Kv10-Kv12, respectively) are likely to interact with the gate surroundings in the transmembrane core. S4 segment is also depicted as a reference. See text for details.

nucleotide-gated $(\mathrm{HCN})$ and $\mathrm{BK} / \mathrm{K}_{\mathrm{Ca}} 1$ channels] and those gated exclusively by intracellular ligands [cyclic nucleotide-gated (CNG) and $\mathrm{SK} / \mathrm{K}_{\mathrm{Ca}} 2$ ]. Besides these "cytoplasmic cores", a panoply of protein domains and motifs (Figure 4) can be present in the cytoplasmic regions that, in addition to some accessory subunits, add diversification in structure, function, and regulation to the different channel subfamilies and even to different members of the same subfamily.

Examples of cytoplasmic domains for which the tridimensional structure has been solved, include the cited T1 domain (Kreusch et al., 1998; Bixby et al., 1999; Gulbis et al., 2000; Minor et al., 2000; Scannevin et al., 2004; Long et al., 2005a; Pioletti et al., 2006), the distal N-terminus inactivation structures from Kv3.4, ShakerB, and Kv1.4 (Antz et al., 1997; Schott et al., 1998; Wissmann et al., 2003), the N-terminal PAS domain and its initial distal segments from Kv11.1 (Morais-Cabral et al., 1998; Li et al., 2010; Muskett et al., 2011; Ng et al., 2011), and the C-terminal coiled-coil segment from Kv7.4 and Kv7.1 (Howard et al., 2007; Wiener et al., 2008). It is also interesting to note the current availability of high-resolution tridimensional structures for the $\mathrm{C}$-terminal $\mathrm{C}$-linker/cNBD regions of the Kv-related HCN and CNG channels (Zagotta et al., 2003; Schünke et al., 2011), providing a valuable reference for homologous regions present in some Kv channels such as those of the eag family.

Additionally, several regions putatively involved in different aspects of channel behavior other than gating (e.g., oligomerization and assembly, trafficking, surface expression, protein-protein interactions, modulation, or drug-channel interactions) have been recognized in the Kv cytoplasmic channel regions (Figure 4; Hopkins et al., 1994; Xu et al., 1995; Ponce et al., 1997; Kupershmidt et al., 1998; Schulteis et al., 1998; Bentley et al., 1999; Cukovic et al., 2001; Yang et al., 2001; Leung et al., 2003; Kunjilwar et al., 2004; Callsen et al., 2005; Choi et al., 2005; Xu et al., 2010; Zheng et al., 2010), that in many cases have not been associated to a known tridimensional structure. Finally, the availability of lowresolution images for some voltage-dependent $\mathrm{K}^{+}$channels yields interesting possibilities to fit with partial X-ray data, and provides significant new insights into the overall architecture of the channel molecule (Sokolova et al., 2001, 2003; Orlova et al., 2003; Parcej and Eckhardt-Strelau, 2003; Kim et al., 2004; Adair et al., 2008; Pischalnikova and Sokolova, 2009; Wang and Sigworth, 2009).

ROLE OF CYTOPLASMIC DOMAINS IN INACTIVATION GATING A pioneering indication that some cytoplasmic region(s) could participate in the control of gating behavior was provided by analyzing the process of inactivation. Thus, the specific abolition of voltage-dependent $\mathrm{Na}^{+}$current inactivation by intracellular treatment with proteolytic enzymes (Armstrong et al., 1973) subsequently led to the proposal of a "ball-and-chain" mechanism as the determinant of this inactivation process (Armstrong and Bezanilla, 1977). However, a better molecular explanation of this mechanism, in which a cytoplasmic blocking particle tethered to the channel protein (the "ball," see Figures 1 and 4) binds rapidly to the pore and plugs it after the activation gate opens, was obtained in 1990 by studying the fast/N-type-inactivation of the Kv-type Shaker $\mathrm{K}^{+}$channel of Drosophila. Thus, deletion of the first $\approx 20$ amino acids of the amino terminus eliminated rapid inactivation (Hoshi et al., 1990), whereas a soluble peptide containing that sequence restored inactivation in a concentration-dependent manner (Zagotta et al., 1990). It was subsequently observed that the soluble peptide (or N-terminal inactivation domain) competes with intracellularly applied channel blockers (e.g., quaternary amines, Choi et al., 1991), that it is expelled to the cytoplasm by potassium flow from the extracellular side of the membrane (Demo and Yellen, 1991), and that the inactivation process traps the channel in an open-inactivated state that prevents it from closing, making the recovery of inactivation typically via the open state 


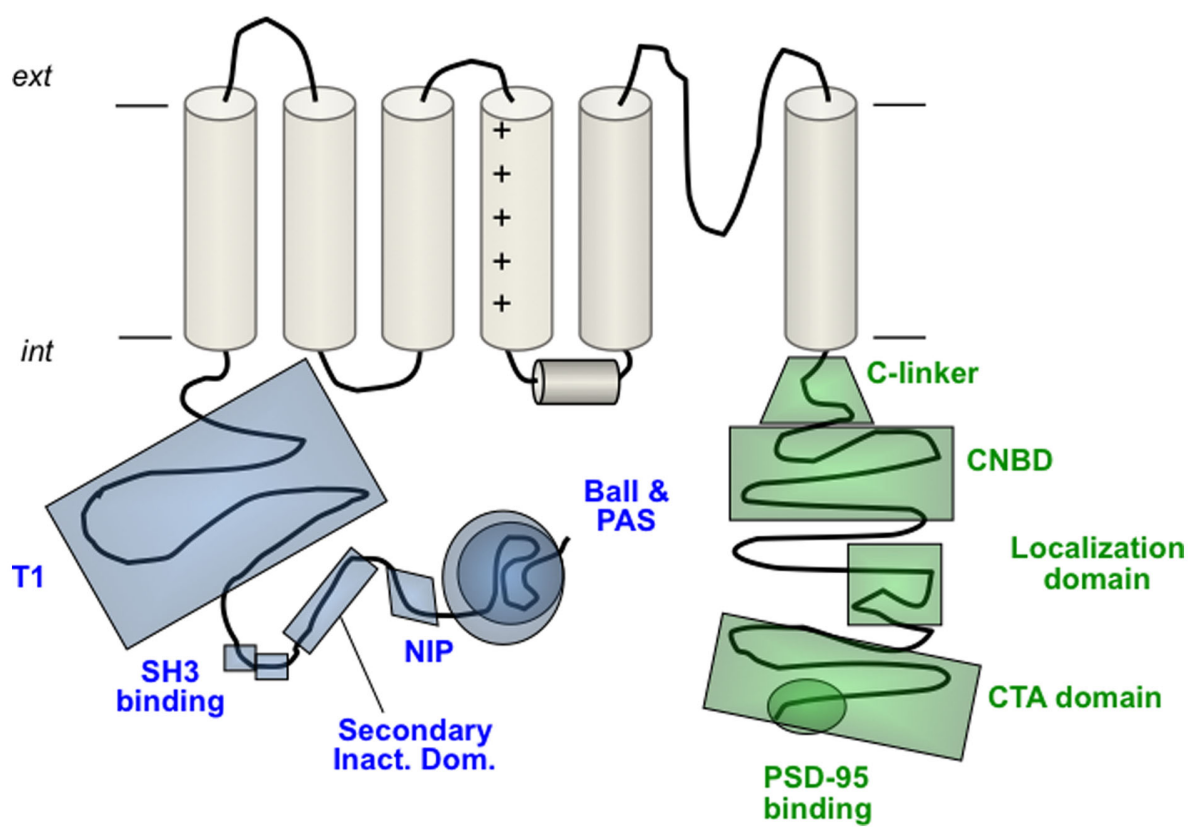

FIGURE 4 | Schematic view of different structural and/or functional domains recognized at the cytoplasmic ends of $\mathbf{K v}$ channels. In the amino terminus these include the ball-like structure responsible for fast $\mathrm{N}$-type inactivation, the eag/PAS domain of the eag-like channels, the NIP domain that protects Kv1.6 channels against rapid inactivation, the secondary inactivation domain reported for Kv1.4 channels, the double SH3 binding domain of Kv1.5, and the T1 tetramerization domain (also called NAB) of the
Kv1-Kv4 channels. In the carboxy terminus the domains shown correspond to the C-linker and cNBD encountered in the eag-like channels, the localization domain and the C-terminal activation (CTA) domain of Kv2.1 and the post-synaptic density protein (PSD-95)-binding domain of some Kv1 channels. A more detailed view of the Kv7 channels carboxy terminus organization is shown schematically in Figure 6. For more explanations, see text. Note that not all the depicted domains pertain to the same Kv channel.
(Demo and Yellen, 1991; Ruppersberg et al., 1991). Moreover, the inactivation domain was shown to interact with a binding site in the pore cavity, which overlaps with the binding site for quaternary amine blockers (Zhou et al., 2001; Gonzalez et al., 2011).

Some aspects of the ball-and-chain inactivation mechanism are worthy of further consideration, since the structural arrangements of the "chain" are not as clear as those of the "ball." Thus, shortening the length of the Shaker chain accelerated inactivation rates (Hoshi et al., 1990) as if this region were acting as a flexible linker to tether the ball to the channel. However, some Kv1.4 deletions that reduce the length of the "chain" not only do not increase the rate of inactivation, but actually slow inactivation as if the specific structure of this region could affect the movement and/or orientation of the inactivating particle (Rasmusson et al., 1998). It has also been suggested that rather than being a simple tether, this "chain" region may act in concert with other cytoplasmic structures to orientate and constrain the movement of the inactivation particle (Isacoff et al., 1991; Jern and Covarrubias, 1997; Sankaranarayanan et al., 2005; Baker et al., 2006). In this sense, it has been proposed that interactions of the Kv1.1 T1 domain with the more distal N-terminal structures play an important role in defining the strength of the ball-triggered N-type inactivation (Baker et al., 2006) and it has also been recognized that ball interaction(s) with the T1 domain and the S4-S5 linker seem to be crucial for proper development of the fast/N-type inactivation (Isacoff et al., 1991; Holmgren et al., 1996; Baker et al., 2006). Thus, in contrast with the well defined position of the ball plugging the conduction pathway inside the pore to inactivate the channel, the resting position of the chain segments and their dynamic rearrangements during the closed to open and inactive transitions are not well known. There is indirect evidence supporting the interpretation that these structures might wrap around the scaffold provided by the $\mathrm{T} 1$ tetramer hanging below the channel core (Figure 3A), so that upon depolarization they would snake through the windows lined by the S1-T1 linkers to reach a pocket on the upper T1 domain surface and subsequently the channel cavity below the selectivity filter (Gulbis et al., 2000; Kobertz et al., 2000; Zhou et al., 2001; Baker et al., 2006). However, it has also been proposed that the ball-andchain combination is confined to the space between the T1 domain and the transmembrane portion of the channel (Varhsney et al., 2004).

In addition to the ball, a second inactivating domain with the ability to endow the channel with rapid inactivation has been identified in a more proximal part of the $\mathrm{N}$-terminus of some $\mathrm{Kv}$ channels (e.g., Kv1.4; Kondoh et al., 1997; Höllerer-Beitz et al., 1999; Wissmann et al., 2003), and an N-type inactivation-prevention (NIP) domain (Figure 4) has been mapped close to the Kv1.6 N-terminal end (Roeper et al., 1998). As an alternative to the ball and length-dependent chain mechanism, a fast inactivation mechanism has been proposed for Kv1.4, based on electrostatic interactions between oppositely charged $\mathrm{N}$-terminal segments and between the positively charged inactivation ball and acidic residues of the T1-S1 linker, that shorten the distance between the inactivating particle and its binding site, helping to orientate the ball 
and causing the channel to inactivate more efficiently (Fan et al., 2012).

It is important to mention that even though a similar architecture is maintained around the gating machinery, the functional effects of the cytoplasmic domains can vary among channels even belonging to the same subfamily. This is the case of the fast inactivating A-type $\mathrm{Kv} 4$ channels, in which the existence of a $\mathrm{N}$-type inactivation mechanism and a ball-like inactivating peptide at the N-terminus have been recognized (Gebauer et al., 2004), although it seems to play a minor role since the $\mathrm{Kv} 4$ most prominent inactivation is based in a temporary loss of coupling between the voltage sensor and the cytoplasmic gate (Barghaan et al., 2008; Barghaan and Bähring, 2009). Remarkably, the development of Kv4 inactivation is determined by the presence of amphipathic N-terminal sequences and a positively charged domain at the C-terminus, that may interact with each other (Jern and Covarrubias, 1997; Hatano et al., 2004).

As indicated above (see Figure 1), collapsing of the selectivity filter during depolarization steps can lead to a second type of inactivation named "C-type inactivation" (or "selectivity filter gating"; Wang et al., 2011). Recent data from some prototypical $\mathrm{K}^{+}$ channels (e.g., KcsA and Kir) have provided a structural basis for allosteric coupling between activation at the level of the internal membrane surface and this type of inactivation at the channel selectivity filter, and about the influence exerted on them by intracellular domains (Uysal et al., 2011; Clarke et al., 2010; Cuello et al., 2010; Zhou and Jan, 2010). This yields some new ideas about how the structural modifications in the cytosolic domains can be allosterically transmitted to the intracellular gate and even to more distant gating elements in the channel core. It is important to note that selectivity filter gating not only pertains to KcsA and Kir voltage-independent $\mathrm{K}^{+}$channels containing exclusively a pore domain (Norton and Gulbis, 2010), but also to a wide range of $\mathrm{Kv}$ channels, to other highly selective $\mathrm{K}^{+}$channels such as SK and $\mathrm{BK}_{\mathrm{Ca}}$, and to non-selective cation channels (e.g., CNG channels) related to the Kv family (Bruening-Wright et al., 2007; Cox and Hoshi, 2011; Wang et al., 2011) in which the gating motions around the S6 bundle cross and hence the coupled selectivity filter rearrangements, can also be influenced by conformational changes in the cytoplasmic domains.

\section{IMPLICATION OF CYTOPLASMIC DOMAINS IN ACTIVATION/DEACTIVATION GATING OF T1-CONTAINING Kv CHANNELS}

The Kv channel's activation gate is located at the intracellular end of the pore at the C-terminus of the S6 transmembrane segment (Armstrong, 1971; Holmgren et al., 1997, 1998; Liu et al., 1997; Perozo et al., 1999; del Camino et al., 2000; del Camino and Yellen, 2001; Hackos et al., 2002; Webster et al., 2004; Wynia-Smith et al., 2008). Although other contacts and interactions between different domains could be involved (Ding and Horn, 2003; Li et al., 2008; Labro et al., 2011), coupling of the voltage sensor movement to operation of the gate mainly involves the S4-S5 linker which seems to act as a structural link, influencing gate dynamics via physical interaction(s) with the intracellular end of S6 and/or the cytoplasmic "C-linker" region (Figure 4) following it (Lu et al., 2002; Tristani-Firouzi et al., 2002; Ding and Horn, 2003; Long et al., 2005b; Ferrer et al., 2006; Boulet et al., 2007; Labro et al., 2008, 2011; Nishizawa and Nishizawa, 2009; Choveau et al., 2011). Interestingly, a similar coupling via S4-S5 linker interaction with the cytoplasmic end of S6 has been proposed for HCN and KAT1 channels (Chen et al., 2001; Decher et al., 2004; Prole and Yellen, 2006), that show an overall structure very similar to that of Kv channels, but in which opening is triggered by membrane hyperpolarization rather than depolarization (Männikkö et al., 2002; Latorre et al., 2003; Vemana et al., 2004; Grabe et al., 2007). This opposite polarity of gating is perhaps achieved by a different binding of the S4-S5 linker to the extreme of S6 only in the open state whereas in the Kv channels this interaction takes place in the closed state (Choveau et al., 2011).

Since the gate and the sensor-gate coupler (i.e., the S4-S5 linker) locate at the cytoplasmic channel surface, these structures become accessible targets for modulation from the cytoplasmic milieu, providing attractive means of channel activity regulation not only by amino- and /or carboxy-located channel domains but also by soluble products of signal transduction cascades. One example of channel gating modulation by cytoplasmic domains is that of Kv2.1. Early work with Kv2.1 indicated that the activation gating could be strongly affected by the cytoplasmic amino and carboxyl termini (VanDongen et al., 1990), and the influence of the channel amino terminus in voltage-dependent gating and modulation has been subsequently confirmed (Pascual et al., 1997). It has been demonstrated that interactions between the $\mathrm{N}$ - and $\mathrm{C}$ terminal regions of Kv2.1 lacking auxiliary $\beta$ subunits determine its activation properties, trafficking, and phosphorylation-dependent modulation (Ju et al., 2003; Scholle et al., 2004; Mohapatra et al., 2008 ), in a way that resembles the interaction between the $\alpha$ and the auxiliary $\beta$ subunits in other $\mathrm{Kv}$ channels (Mohapatra et al., 2008). Another case is that of Kv1.2, in which an interaction between the C-terminus and the S4-S5 linker of a neighboring subunit which is able to regulate channel activation has also been suggested (Zhao et al., 2009). It has also been reported that the polar T1 surfaces of the mammalian Kv1.2 and the Aplysia Kv1.1 channels play a key role in the conformational changes that lead to channel opening (Cushman et al., 2000; Minor et al., 2000). More recently, use of fluorescence resonance energy transfer (FRET) microscopy combined with voltage-clamp recording has allowed the detection of conformational rearrangements in the relative orientation of Kv1.2 N- and C-termini upon depolarization (Kobrinsky et al., 2006; Lvov et al., 2009), a mechanism that could be related to gating regulation and that may also pertain to other $\mathrm{Kv}$ channels. Interestingly, similar gating-related motions of the $\mathrm{N}$ - and C-termini have been detected in Kv7.1 and the CNGA1 channel using an equivalent approach (Taraska and Zagotta, 2007; Haitin et al., 2009), although both channels belong to the subgroup characterized by the absence of the T1 domain (see above). Finally, in the case of $\mathrm{Kv} 4$ channels, it has been demonstrated that the T1-T1 interface is functionally active and dynamic during gating (Wang et al., 2005) and, based on work with Kv4.1 channels, it has been concluded that the complex voltage-dependent gating rearrangements of eukaryotic Kv channels are not limited to the membrane-spanning core, but must include the intracellular T1-T1 interface (Wang and Covarrubias, 2006). 


\section{CYTOPLASMIC DOMAINS AND ACTIVATION/DEACTIVATION GATING OF eag-TYPE Kv CHANNELS}

An interesting contribution to the topic of gating control by cytoplasmic domains is provided by members of the eag family, that comprises the Kv10-Kv12 subfamilies (Warmke and Ganetzky, 1994). Overall sequence similarity between eag-and Shaker-type $\mathrm{Kv} 1-\mathrm{Kv} 4$ channels is quite low except for the pore region, but a much higher degree of homology is found between eag-type channels and CNG, $\mathrm{HCN}$, and inwardly rectifying plant $\mathrm{K}^{+}$channels (Anderson et al., 1992; Sentenac et al., 1992; Warmke and Ganetzky, 1994; Yu et al., 2005).

Kv10 (ether-á-go-go or eag) channels are involved in setting the membrane potential in several cell types and appear to be related to processes like cell-cycle, proliferation, and tumor progression (Felipe et al., 2006; Arcangeli et al., 2009; Wulff et al., 2009; Asher et al., 2010). Several studies have demonstrated the involvement of cytoplasmic domains in the control of eag channel gating. Thus, it has been observed that the most distal region and the PAS domain at the N-terminus of the eag channels are involved in determining gating kinetics (Terlau et al., 1997; Stevens et al., 2009; Wray, 2009), and that alterations in eag gating following truncation of the initial portion of the $\mathrm{N}$-terminus can be compensated by mutation of the voltage sensor S4 segment (Terlau et al., 1997). It has also been shown that the voltage dependence of eag currents is not determined solely by the membrane-spanning domains (Lörinczi et al., 2009), and that the N- and C-terminal regions could be involved in controlling a gating step after movement of the voltage sensor, as well as in regulating biophysical properties of the channel ( $\mathrm{Li}$ et al., 2011). Also, voltage-dependent gating characteristics of plant KAT1 channels seem to be influenced by the $\mathrm{N}$ - and C-termini of the protein (Marten and Hoshi, 1997, 1998).

The relationship between cytoplasmic structures and gating properties has been exhaustively investigated in the Kv11.1 (human ether-á-go-go-related gene or hERG) channel, a remarkable entity both from the pathophysiological and the biophysical points of view. hERG mediates the cardiac delayed rectifier potassium current $I_{\mathrm{Kr}}$ (Sanguinetti et al., 1995; Trudeau et al., 1995) and mutations in the hERG gene and drug inhibition of hERG channels underlie inherited and acquired type 2 long-QT syndrome (Sanguinetti et al., 1995; Viskin, 1999; Keating and Sanguinetti, 2001; Redfern et al., 2002; Thomas et al., 2003; Finlayson et al., 2004; Roden and Viswanathan, 2005; Goldenberg and Moss, 2008). On the other hand, hERG channels play a key role in setting the electrical behavior of a variety of non-cardiac cell types (Barros et al., 1994, 1997; Bauer et al., 1999; Schäfer et al., 1999; Cherubini et al., 2000; Emmi et al., 2000; Overholt et al., 2000; Rosati et al., 2000; Arcangeli et al., 2009). These physiological roles of hERG derive from its unusual gating properties, characterized by slow activation kinetics and a very fast inactivation on depolarization. Thus, hERG currents increase during repolarization due to a fast recovery from inactivation followed by a much slower deactivation for which the channels remain open for longer periods of time at negative voltages, giving rise to the typical hERG tail currents. In the case of the heart, this contributes to the repolarization of the cardiac action potential and to the prevention of arrhythmias induced by early after-depolarizations or ectopic beats (Smith et al., 1996; Lu et al., 2001).
As for other voltage-gated potassium channels, voltage sensors and gating elements have been mapped to the transmembrane core of hERG (Smith and Yellen, 2002; Liu et al., 2003; Piper et al., 2003; Subbiah et al., 2004, 2005; Zhang et al., 2004, 2005; Saenen et al., 2006). In the case of hERG a volume larger than the core region hangs toward the cytoplasm since the cytoplasmic regions account for around $80 \%$ of the channel protein (Figure 5), but details about the structural architecture of these extensive regions are still lacking (Miranda et al., 2008). What has been clearly demonstrated is that the distinctive gating properties of hERG are strongly influenced by some cytoplasmic protein domains. Thus, the conserved eag $\mathrm{N}$-terminal domain at the beginning of the hERG N-terminus and the exclusive proximal domain following it up to the S1 segment (Figure 5) were identified as important determinants of the remarkably slow deactivation and activation gating kinetics, respectively (Schönherr and Heinemann, 1996; Spector et al., 1996; Morais-Cabral et al., 1998; Wang et al., 1998; Chen et al., 1999; Viloria et al., 2000; Aydar and Palmer, 2001; Alonso-Ron et al., 2008; Gustina and Trudeau, 2009; Ng et al., 2011). In these studies, it has been repeatedly demonstrated that the N-terminal eag domain determines the slow hERG deactivation, since channels with particular deletions of the amino terminus, or with point mutations in the eag domain, show rapid deactivation kinetics. The fact that short deletions at the beginning of the $\mathrm{N}$-terminus mimic the effect of more extensive amino terminal removal, points to the initial segment of the eag domain (residues 1-26) as the essential regulator of hERG deactivation gating (Wang et al., 1998, 2000; Ng et al., 2011).

Functional reconstitution of mutant channels with a recombinant eag N-terminal fragment, combined with TIRF-FRET spectroscopy, have recently been used to provide some additional insights into the regulation of hERG deactivation (Gustina and Trudeau, 2009; Fernández-Trillo et al., 2011). Thus, it has been recognized that normal slow deactivation gating involves an interaction between the initial N-terminal flexible segment (Figure 5B; Li et al., 2010; Muskett et al., 2011; Ng et al., 2011) and the gating machinery, likely at the level of the S4-S5 linker (Fernández-Trillo et al., 2011). Indeed, it has been shown that physical proximity exists between that unstructured and flexible segment of the hERG amino terminus and the $\mathrm{N}$-terminal portion of the S4-S5 linker (De la Peña et al., 2011), further supporting this interpretation. In this context, the PAS sub-domain from the hERG eag domain and the amphipathic $\alpha$-helix (residues 13-23) could act as a scaffold and a spacer helping to correctly orientate the initial flexible tail of the amino end (residues 2-9) toward the S4-S5 linker to modulate hERG gating (De la Peña et al., 2011; Fernández-Trillo et al., 2011; Ng et al., 2011). Additionally, the extensive contacts of these structures with the top and side surfaces of the C-linker/cNBD domains, that hang centrally below the pore domain in this type of channel (Figures 3B and 5B), could help to allosterically modulate the operation of the cytoplasmic gate at the C-terminus of the S6 segment, which is directly attached to the C-linker (Muskett et al., 2011; Gustina and Trudeau, 2011). In fact, the involvement of some residues of the C-linker/cNBD regions of the hERG carboxy terminus in the control of deactivation gating through their interaction with the $\mathrm{N}$-terminal-most region has also been proposed (Al-Owais et al., 2009; Kolbe et al., 2010; Muskett et al., 2011). 
A

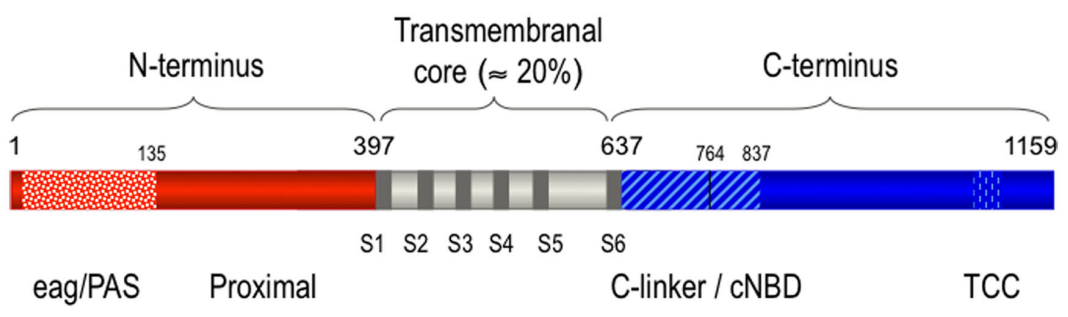

B

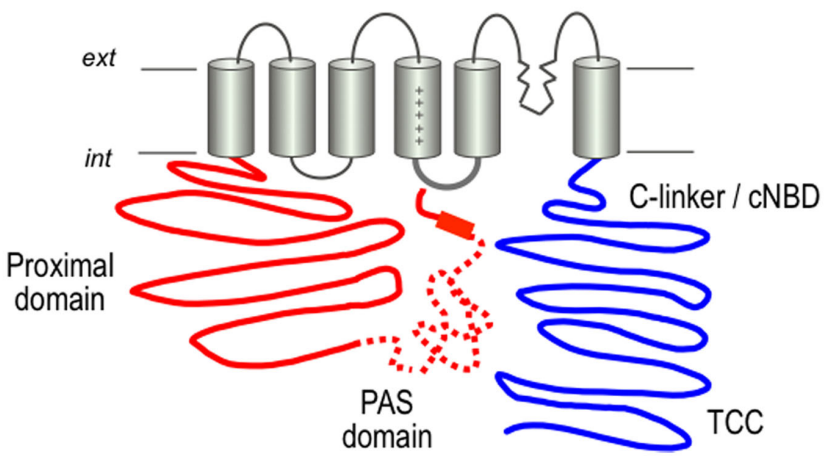

FIGURE 5 | Structural organization of the hERG $\mathrm{K}^{+}$channel. (A) Schematic linear diagram of the hERG channel protein. The regions corresponding to the eag/PAS (residues 1-135) and the proximal domains up to the first transmembrane helix are shown as striped and solid red bars, respectively. The transmembranal core region containing the six transmembrane helices and the carboxy terminus are shown colored in gray and blue, respectively. TCC indicates the proposed location of a tetramerization coiled-coil at the C-terminus. The size of every domain is represented on a horizontal scale proportional to the total length of the protein. (B) Schematic representation of a hERG channel $\alpha$-subunit showing the proposed relative positioning of the PAS region in the amino terminus (dotted line), and the flexible tail of the amino end (initial solid red line segment) and the amphipathic $\alpha$-helix separating them (red rectangle) pointing toward the S4-S5 linker on the cytoplasmic surface of the channel core. The proximity between the initial regions of the $\mathrm{N}$-terminus and the $\mathrm{C}$-linker/CNBD domains that are directly linked to the cytoplasmic gate at the bottom of helix S6 is also used to illustrate the possible existence of additional interactions between these channel structures. For more explanations, see text.
On the other hand, it has also been demonstrated that the hERG proximal domain (Figure 5) plays an important role in the activation channel properties and their modulation by hormones (Viloria et al., 2000; Gómez-Varela et al., 2002, 2003; Alonso-Ron et al., 2008, 2009). A small cluster of basic residues within this proximal domain close to the S1 segment has been subsequently recognized as a determinant of the hERG activation behavior through an electrostatic influence on the gating machinery (Saenen et al., 2006). However, although the modulation of hERG activation gating by a $G$ protein-coupled hormone receptor is impaired after deletion of the proximal domain, it is observed in the absence of the cluster of basic residues (Gómez-Varela et al., 2003; Alonso-Ron et al., 2009). Interestingly, kinetic measurements of hERG activation under steady-state conditions, indicated that the initial region of the eag domain also affects the activation behavior (Alonso-Ron et al., 2008), suggesting that an interaction of this region with the channel core may also be involved in the modifications of gating caused by the deletion of the proximal domain (Viloria et al., 2000; Alonso-Ron et al., 2008). Nevertheless, the exact regions of the gating machinery at which the regulatory effects on activation are exerted remain to be established, although the bottom part of S4, the S4-S5 linker, the C-terminal portion of S6 and the C-linker/cNBD regions have been considered as possible candidates (Viloria et al., 2000; Tristani-Firouzi et al., 2002; Saenen et al., 2006; Alonso-Ron et al., 2008; De la Peña et al., 2011; Gustina and Trudeau, 2011).

Therefore, the long cytoplasmic domains of hERG exert important contributions to its unusual gating properties, supporting the interpretation that physical interactions between cytoplasmic domains and/or between them and the transmembrane channel core may also constitute an essential component of the gating machinery in other Kv channels.

\section{ROLE OF CYTOPLASMIC Kv DOMAINS IN MODULATION OF CHANNEL GATING BY SIGNAL TRANSDUCTION ELEMENTS}

Due to their accessibility to inner cell components, the cytoplasmic domains of $\mathrm{Kv}$ channels are obvious targets for cell-physiological control of channel function. Some illustrative cases are the regulation of Kv1.1 inactivation by concurrent direct binding of syntaxin and $\mathrm{G}$ protein $\beta \gamma$ subunits (Michaelevski et al., 2002), the inhibition of human Kv10.1 channels by $\mathrm{Ca} / \mathrm{calmodulin}$ binding to the $\mathrm{N}$ - and C-terminal structures (Ziechner et al., 2006), 
the dependence of Kv11.1 rERG hormonal modulation on the presence of the $\mathrm{N}$-terminal splicing variant erglb (Kirchberger et al., 2006), and the modulation of Kv2.1 gating by binding of the SNARE complex components to the cytoplasmic channel tails (He et al., 2006). Also, two paradigmatic examples, the calmodulin modulation of Kv7 channels via their C-terminus, and the widespread regulation of channel function by protein phosphorylation, are considered next.

Kv7 (KCNQ) channels are a subfamily of Kv channels of great physiological importance in the kidney, gastro-intestinal tract, brain, and heart. In fact, there are several mutations in human Kv7 genes that lead to cardiac and neurological disorders such as long-QT syndrome and neonatal epilepsy (reviewed in Ashcroft, 2006; Haitin and Attali, 2008; Maljevic et al., 2010). Kv7 channels exhibit, as a distinctive feature, a C-terminus much longer than that of other $\mathrm{Kv}$ channels, which is critical for Kv7 assembly and trafficking, and also gating (reviewed in Haitin and Attali, 2008), and thus some Kv7 associated channelopathies involve mutations or alterations in this domain (Wen and Levitan, 2002; Haitin and Attali, 2008; Zheng et al., 2010). The Kv7 C-terminus contains several structural motifs including coiled-coils, calmodulin-binding structures, and basic amino acid clusters (Figure 6). Also, calmodulin interacts with the C-terminus of Kv7.1-Kv7.5 (Yus-Nájera et al., 2002; Haitin and Attali, 2008), an association that has also been demonstrated by TIRF/FRET techniques to take place in living mammalian cells (Bal et al., 2008). Although calmodulin can be constitutively tethered to Kv7 channels both in the absence or presence of $\mathrm{Ca}^{2+}$ (Wen and Levitan, 2002; Shahidullah et al., 2005), these interactions are likely to have $\mathrm{Ca}^{2+}$-dependent and $\mathrm{Ca}^{2+}$-independent components (Bal et al., 2008; Alaimo et al., 2009). Thus, it has been proposed that the calmodulin-binding module at the Kv7 C-terminus is endowed with a dual regulatory function: a $\mathrm{Ca}^{2+}$ sensor function that affects gating, and a second role in folding and trafficking mediated by a binding site with high affinity for calmodulin (Haitin and Attali, 2008). Interestingly, the calmodulin-binding module at the Kv7 C-termini seems to physically and functionally overlap with a phosphatidylinositol 4,5-bisphosphate $\left(\mathrm{PIP}_{2}\right)$-binding site, allowing a more complex and sophisticated modulation of channel properties (Haitin and Attali, 2008; Hernandez et al., 2008; Bal et al., 2010). Thus, in Kv7.2/Kv7.3 heteromers that mediate the neuronal " $M$ current," channel activity is enhanced by $\mathrm{PIP}_{2}$ and suppressed by $\mathrm{Ca}^{2+} /$ calmodulin (Gamper and Shapiro, 2003, 2007; Zhang et al., 2003; Gamper et al., 2005; Suh and Hille, 2005; Hernandez et al., 2008). In contrast, both $\mathrm{PIP}_{2}$ and $\mathrm{Ca}^{2+} /$ calmodulin seem to activate Kv7.1 channels mediating the cardiac $I_{\mathrm{Ks}}$ current (Loussouarn et al., 2003; Shamgar et al., 2006). Remarkably, disruption of $\mathrm{Ca}^{2+} /$ calmodulin binding to Kv7.2 is associated with neonatal epilepsy (Etxeberria et al., 2007; Haitin and Attali, 2008), and mutations impairing $\mathrm{PIP}_{2}$ or calmodulin binding to Kv7.1 lead to certain forms of cardiac long-QT syndrome (Park et al., 2005; Ghosh et al., 2006; Shamgar et al., 2006).

Phosphorylation constitutes the most common covalent posttranslational modification in eukaryotes (Cohen, 2001) and it can be an important modulatory mechanism for ion channel function, since the presence of phosphorylation targets for one or more kinases potentially allows for sensitive, dynamic, and reversible tuning of the structural and functional status of the protein (Levitan, 1994; Jonas and Kaczmarek, 1996; Park et al., 2008; Cerda and Trimmer, 2010). The exposure of the cytoplasmic domains to the internal cell environment makes them suitable molecular targets for phosphorylation-mediated modulation of channel activity. They can also act as sites of interaction with modulatory partners able to recruit targeting proteins such as phosphatases and kinases leading to the phosphorylation-dependent regulation of gating (Kass et al., 2003). Among those motifs, a C-terminally located leucine zipper is involved in recruiting, via an adaptor protein, a signaling complex including protein kinase A (PKA) and protein phosphatase 1 , that are required for $\beta$-adrenergic receptor modulation of cardiac Kv7.1 (Marx et al., 2002). Indeed, several phosphorylated residues located in the $\mathrm{N}$ - and C-termini have been recognized as targets for regulation of $\mathrm{Kv}$ gating properties. Thus, the C-terminal Kv2.1 cytoplasmic domain can act as an autonomous domain sufficient to transfer Kv2.1-like clustering, voltage-dependent activation, and cholinergic modulation to diverse Kv channels (Mohapatra and Trimmer, 2006), and direct phosphorylation of its distal end alters channel voltage-dependent activation (Murakoshi et al., 1997). Interestingly, differential phosphorylation at a specific subset of sites, instead of the utilization of cell-specific phosphorylation sites, can explain differences in gating properties of Kv2.1 in different cell types under basal conditions, and in the same cell type under basal versus stimulated conditions (Park et al., 2007). Some other cases of gating regulation by phosphorylation of cytoplasmic domains have been less studied but are also illustrative: (i) Tyrosine kinase-dependent suppression of Kv1.2 by phosphorylation of an N-terminal residue has been observed, and antagonization of this effect by recruiting a protein tyrosine phosphatase to the $\mathrm{N}$ - and C-termini of the channel has also been shown (Huang et al., 1993; Tsai et al., 1999). (ii) Inactivation gating parameters of Shaker and Kv3.4 channels have been reported to be modulated by PKA-dependent phosphorylation of the $\mathrm{C}$-terminus and protein kinase $\mathrm{C}(\mathrm{PKC})$-dependent phosphorylation of the $\mathrm{N}$-terminal inactivation particle, respectively (Covarrubias et al., 1994; Drain et al., 1994; Beck et al., 1998; Antz et al., 1999). (iii) It is known that some N- and C-terminal Kv4.2 residues can be phosphorylated by PKA and MAPK, respectively, and that some cross-talk between these phosphorylation loci can exist (Adams et al., 2000; Anderson et al., 2000; Schrader et al., 2009), but the functional consequences of such an interaction still remain obscure. (iv) $\mathrm{Ca}$ /calmodulin-dependent protein kinase II phosphorylates C-terminally located sites of Drosophila eag channels and modulates their function (Whang et al., 2002). (v) It has been shown that phosphorylation of the S4-S5 linker of neuronal KCNQ (Kv7) channels inhibits them (Surti et al., 2005). (vi) The state of phosphorylation of the Kv1.1 C-terminus regulates the extent of inactivation conferred by the $\operatorname{Kv} \beta 1.1$ subunit through a mechanism related to the interaction of the $\alpha \beta$ channel complex with the microfilaments via a PSD-like protein (Jing et al., 1997). All these data constitute overwhelming evidence that phosphorylation of cytoplasmic domains is a widespread mechanism of reversible gating modulation in $\mathrm{Kv}$ channels.

A promising addition to the study of channel modulation by phosphorylation is the use of phosphoproteomic approaches to identify the channel target residues of the phosphorylation events 


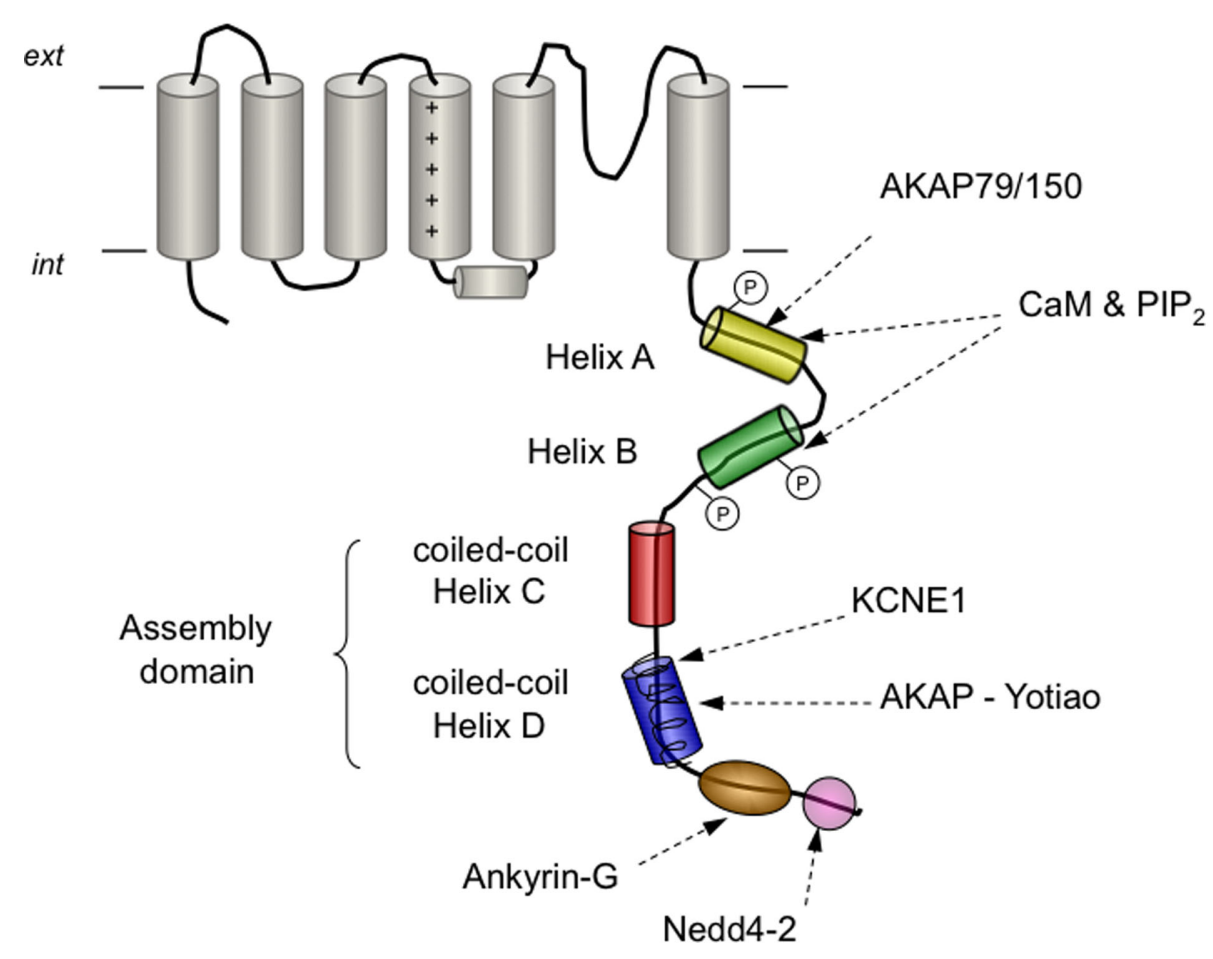

FIGURE 6 | Schematic representation of the carboxy-terminal tail structures and/or interaction sites present in Kv7 channels. The four helical regions (helices A-D) conserved in all family members are shown as cylinders. Formation of coiled-coil assemblies at the level of helices $C$ and $D$ is indicated. The proposed location of the conserved interaction sites with calmodulin (CaM) and phosphatidylinositol 4,5-bisphosphate
$\left(\mathrm{PIP}_{2}\right)$, with A-kinase anchoring protein 79/150 (AKAP79/150) in Kv7.2, with the auxiliary $\beta$ subunit KCNE1 in Kv7.1, with AKAP-Yotiao in Kv7.1, with ankyrin-G in Kv7.2-Kv7.3 and with ubiquitin-protein ligase Nedd4-2 in Kv7.1 and Kv7.2-Kv7.3, are also shown. Phosphorylation sites by Src kinase in helix $A$ and by protein kinase $C$ in helix $B$ are indicated by an encircled $P$. (reviewed in Cerda and Trimmer, 2010; Cerda et al., 2010; Baek et al., 2011). This method has allowed identification of $\mathrm{N}$ - and C-terminal phosphosites on $\alpha$ subunits of Kv1.1-Kv1.6, Kv2.1$\mathrm{Kv} 2.2, \mathrm{Kv} 3.1-\mathrm{Kv} 3.4, \mathrm{Kv} 4.1-\mathrm{Kv} 4.3$, and Kv7.2-Kv7.5, although the functional significance of most of these phosphosites has not yet been determined. This aspect is quite relevant, since even though a phosphorylation mechanism may be involved in channel regulation, it is possible that the phosphate modification does not take place in the channel protein itself (Vacher and Trimmer, 2011). On the other hand, an agonist-dependent change in the basal phosphorylation level of the channel molecule may not cause a concomitant modification of the gating or other channel properties. An illustrative case of some of these concerns is provided by the hormonal modulation of the Kv11.1 (ERG) channel gating. Thus, early studies about the mechanism of ERG channels inhibition by thyrotropin-releasing hormone in adenohypophysial cells, pointed to a phosphorylation event as determinant of the hormonal induced response (Delgado et al., 1992; Barros et al., 1993, 1998). Further work demonstrated that the cytoplasmic $\mathrm{N}$-terminal proximal domain was required for hormonal modulation of hERG gating (Gómez-Varela et al., 2003). Subsequently, it has been proposed that the PKC-dependent modulation of hERG is exerted either independently of direct phosphorylation of the channel protein itself in Xenopus oocytes (Thomas et al., 2003, 2004), or via a direct phosphorylation of the pore forming hERG subunits in mammalian cells (Cockerill et al., 2007). In this sense, the possibility that the cell types differentially supply molecular components of the signaling pathways involved in the channel modulation (Miranda et al., 2005), should also be considered. Interestingly, a direct phosphorylation of the hERG cytoplasmic domains by PKA is involved in the regulation triggered by activation of $\beta$-adrenergic receptors (Thomas et al., 1999; Cui et al., 2000, 2001; Kiehn, 2000; Kagan et al., 2002; Karle et al., 2002), and some signaling cross-talk between PKC and PKA cannot be excluded.

In summary, either by directly affecting the gating machinery or by influencing it in response to cellular modulators, $\mathrm{Kv}$ cytoplasmic regions constitute important regulators of voltagedependent channel gating. Unfortunately, the striking advances characterizing the tridimensional structures of some channel core constituents have not been paralleled by similar success regarding the architecture of the cytoplasmic regions. Whereas physical interactions between the cytoplasmic domains and/or between them and the transmembranal channel core clearly constitute essential components of the gating machinery, details about dynamic conformational rearrangements in these regions during channel functionality remain mostly unknown. Combining structural studies with other fluorimetric, spectroscopic, and biophysical functional approaches could provide a better understanding of the dynamic steps connecting the discrete conformations resolved in the crystallographic structures. 


\section{ACKNOWLEDGMENTS}

This work was supported by the Spanish Ministerio de Ciencia e Innovación (MICINN) by grant BFU2009-11262 and a Consolider-Ingenio project (SICI; CSD2008-00005). The authors

\section{REFERENCES}

Adair, B., Nunn, R., Lewis, S., Dukes, I, Philipson, L., and Yeager, M. (2008). Single particle image reconstruction of the human recombinant Kv2.1 channel. Biophys. J. 94, 2106-2114.

Adams, J. P., Anderson, A. E., Varga, A. W., Dineley, K. T., Cook, R. G., Pfaffinger, P. J., and Sweatt, J. D. (2000). The A-type potassium channel $\mathrm{Kv} 4.2$ is a substrate for the mitogen-activated protein kinase ERK. J. Neurochem. 75, 2277-2287.

Alaimo, A., Gómez-Posada, J. C., Aivar, P., Etxeberría, A., Rodriguez-Alfaro, J. A., Areso, P., and Villarroel, A. (2009). Calmodulin activation limits the rate of KCNQ2 $\mathrm{K}^{+}$ channel exit from the endoplasmic reticulum. J. Biol. Chem. 284, 20668-20675.

Alonso-Ron, C., Barros, F., Manso, D. G., Gómez-Varela, D., Miranda, P., Carretero, L., Domínguez, P., and de la Peña, P. (2009). Participation of HERG channel cytoplasmic structures on regulation by the $G$ proteincoupled TRH receptor. Pflügers Arch. 457, 1237-1252.

Alonso-Ron, C., de la Peña, P., Miranda, P., Domínguez, P., and Barros, F. (2008). Thermodynamic and kinetic properties of amino-terminal and S4-S5 loop HERG channel mutants under steady-state conditions. Biophys. J. 94, 3893-3911.

Al-Owais, M., Bracey, K., and Wray, D. (2009). Role of intracellular domains in the function of the herg potassium channel. Eur. Biophys. J. 38, 569-576.

Anderson, A. E., Adams, J. P., Qian, Y., Cook, R. G., Pfaffinger, P. J., and Sweatt, J. D. (2000). Kv4.2 phosphorylation by cyclic AMP-dependent protein kinase. J. Biol. Chem. 275, 5337-5346.

Anderson, J. A., Huprikar, S. S., Kochian, L. V., Lucas, W. J., and Gaber, R. F. (1992). Functional expression of a probable Arabidopsis thaliana potassium channel in Saccharomyces cerevisiae. Proc. Natl. Acad. Sci. U.S.A. 89, 3736-3740.

Antz, C., Bauer, T., Kalbacher, H., Frank, R., Covarrubias, M., Kalbitzer, H. R., Ruppersberg, J. P., Baukrowitz, T., and Fakler, B. (1999). Control of $\mathrm{K}^{+}$ channel gating by protein phosphorylation: structural switches of the inactivation gate. Nat. Struct. Biol. 6, 146-150.

Antz, C., Geyer, M., Fakler, B., Schott, M. K., Guy, H. R., Frank, R., Ruppersberg, J. P., and Kalbitzer, H. R. (1997). NMR structure of inactivation gates from mammalian voltage-dependent potassium channels. Nature 385, 272-275.

Arcangeli, A., Crociani, O., Lastraioli, E., Masi, A., Pilozzi, S., and Becchetti, A. (2009). Targeting ion channels in cancer: a novel frontier in antineoplastic therapy. Curr. Med. Chem. 16, 66-93.

Armstrong, C. M. (1971). Interaction of tetraethylammonium ion derivatives with the potassium channels of giant axons. J. Gen. Physiol. 58, 413-437.

Armstrong, C. M., and Bezanilla, F. (1977). Inactivation of the sodium channel. II. Gating current 567-590.

Armstrong, C. M., Bezanilla, F., and Rojas, E. (1973). Destruction of sodium conductance inactivation in squid axons perfused with pronase. J. Gen. Physiol. 62, 375-391.

Ashcroft, F. M. (2006). From molecule to malady. Nature 440, 440-447.

Asher, V., Sowter, H., Shaw, R., Bali, A., and Khan, R. (2010). Eag and HERG potassium channels as novel therapeutic targets in cancer. World J. Surg. Oncol. 8, 113.

Aydar, E., and Palmer, C. (2001). Functional characterization of the C-terminus of the human etherà-go-go-related gene $\mathrm{K}^{+}$channel (HERG). J. Physiol. 534, 1-14.

Baek, J.-H., Cerda, O., and Trimmer, J. S. (2011). Mass spectrometrybased phosphoproteomics reveals multisite phosphorylation of mammalian brain voltage-gated sodium and potassium channels. Semin. Cell Dev. Biol. 22, 153-159.

Baker, K. A., Hilty, C., Peti, W., Prince, A., Pfaffinger, P. J., Wider, G., Wüthrich, K., and Choe, S. (2006). NMRderived dynamic aspects of N-type inactivation of a $\mathrm{Kv}$ channel suggest a transient interaction with the T1 domain. Biochemistry 45, 1663-1672.

Bal, M., Zaika, O., Martin, P., and Shapiro, M. S. (2008). Calmodulin binding to $\mathrm{M}$-type $\mathrm{K}^{+}$channels assayed by TIRF/FRET in living cells. J. Physiol. 586, 2307-2320. experiments. J. Gen. Physiol. 70,

thank the members of the Hormone Receptors and Ion Channels Group of the University of Oviedo for their scientific and technical contribution and Dr. Kevin Dalton for proofreading the text.

Bal, M., Zhang, J., Hernandez, C. C., Zaika, O., and Shapiro, M. S. (2010). $\mathrm{Ca}^{2+} /$ calmodulin disrupts AKAP79/150 interactions with KCNQ (M-type) $\mathrm{K}^{+}$channels. J. Neurosci. 30, 2311-2323.

Barghaan, J., and Bähring, R. (2009). Dynamic coupling of voltage sensor and gate involved in closed-state inactivation of $\mathrm{Kv} 4.2$ channels. $J$. Gen. Physiol. 133, 205-224.

Barghaan, J., Tozakidou, M., Ehmke, H., and Bähring, R. (2008). Role of N-terminal domain and accessory subunits in controlling deactivation-inactivation coupling of Kv4.2 channels. Biophys. J. 94, 1276-1294.

Barros, F., del Camino, D., Pardo, L. A., Palomero, T., Giráldez, T., and de la Peña, P. (1997). Demonstration of an inwardly rectifying $\mathrm{K}^{+}$ current component modulated by thyrotropin-releasing hormone and caffeine in $\mathrm{GH} 3$ rat anterior pituitary cells. Pflügers Arch. 435, 119-129.

Barros, F., Gomez-Varela, D., Viloria, C. G., Palomero, T., Giráldez, T., and de la Peña, P. (1998). Modulation of human erg $\mathrm{K}^{+}$channel gating by activation of a $\mathrm{G}$ protein-coupled receptor and protein kinase C. J. Physiol. 511, 333-346.

Barros, F., Mieskes, G., del Camino, D., and de la Peña, P. (1993). Protein phosphatase $2 \mathrm{~A}$ reverses inhibition of inward rectifying $\mathrm{K}^{+}$currents by thyrotropin-releasing hormone in GH3 pituitary cells. FEBS Lett. 336, 433-439.

Barros, F., Villalobos, C., García-Sancho, J., del Camino, D., and de la Peña, P. (1994). The role of the inwardly rectifying $\mathrm{K}^{+}$current in resting potential and thyrotropin-releasing hormone-induced changes in cell excitability of $\mathrm{GH} 3$ rat anterior pituitary cells. Pflügers Arch. 426, 221-230.

Bauer, C. K., Schäfer, R., Schiemann, D. Reid, G., Hanganu, I., and Schwarz, J. R. (1999). A functional role of the erg-like inward-rectifying $\mathrm{K}^{+}$current in prolactin secretion from rat lactotrophs. Mol. Cell. Endocrinol. 148, 37-45.

Beck, E. J., Sorensen, R. G., Slater, S. J. and Covarrubias, M. (1998). Interactions between multiple phosphorylation sites in the inactivation particle of a $\mathrm{K}^{+}$channel: insights into the molecular mechanism of protein kinase C action. J. Gen. Physiol. 112, 71-84.

Bentley, G. N., Brooks, M. A., O’Neill, C. A., and Findlay, J. B. (1999). Determinants of potassium channel assembly localized within the cytoplasmic C-terminal domain of Kv2.1. Biochim. Biophys. Acta 1418, 176-184.

Bett, G. C. L., and Rasmusson, R. L. (2008). Modification of $\mathrm{K}^{+}$ channel-drug interactions by ancillary subunits. J. Physiol. 586, 929-950.

Bezanilla, F. (2008). How membrane proteins sense voltage. Nat. Rev. Mol. Cell Biol. 9, 323-332.

Biggin, P. C., Roosild, T., and Choe, S. (2000). Potassium channel structure: domain by domain. Curr. Opin. Struct. Biol. 10, 456-461.

Bixby, K. A., Nanao, M. H., Shen, N. V., Kreusch, A., Bellamy, H., Pfaffinger, P. J., and Choe, S. (1999). $\mathrm{Zn}^{2+}$. binding and molecular determinants of tetramerization in voltagegated $\mathrm{K}^{+}$channels. Nat. Struct. Biol. 6, 38-43.

Boulet, I. R., Labro, A. J., Raes, A. L., and Snyders, D. J. (2007). Role of the S6 C-terminus in KCNQ1 channel gating. J. Physiol. 585, 325-337.

Bruening-Wright, A., Lee, W.-S., Adelman, J. P., and Maylie, J. (2007). Evidence for a deep pore activation gate in small conductance $\mathrm{Ca}^{2+}$. activated $\mathrm{K}^{+}$channels. J. Gen. Physiol. 130, 601-610.

Callsen, B., Isbrandt, D., Sauter, K., Hartmann, L. S., Pongs, O., and Bähring, R. (2005). Contribution of $\mathrm{N}$ - and C-terminal Kv4.2 channel domains to KChIP interaction. $J$. Physiol. 568, 397-412.

Cerda, O., Baek, J.-Y., and Trimmer, J. S. (2010). Mining recent brain proteomic databases for ion channel phosphosite nuggets. J. Gen. Physiol. 137, 3-16.

Cerda, O., and Trimmer, J. S. (2010). Analysis and functional implications of phosphorylation of neuronal voltage-gated potassium channels. Neurosci. Lett. 486 , 60-67.

Chen, J., Mitcheson, J. S., TristaniFirouzi, M., Lin, M., and Sanguinetti, M. C. (2001). The S4S5 linker couples voltage sensing and activation of pacemaker channels. Proc. Natl. Acad. Sci. U.S.A. 98, 11277-11282. 
Chen, J., Zou, A., Splawski, I., Keating, M. T., and Sanguinetti, M. C. (1999). Long QT syndrome-associated mutations in the Per-Arnt-sim (PAS) domain of HERG potassium channels accelerate deactivation. $J$. Biol. Chem. 274, 10113-10118.

Cherubini, A., Taddei, G. L., Crociani, O., Paglierani, M., Buccoliero, A. M., Fontana, L., Noci, I., Borri, P., Borrani, E., Giachi, M., Becchetti, A., Rosati, B., Wanke, E., Olivotto, M., and Arcangeli, A. (2000). HERG potassium channels are more frequently expressed in human endometrial cancer as compared to non-cancerous endometrium. $\mathrm{Br}$. J. Cancer 83, 1722-1729.

Choi, K. L., Aldrich, R. W., and Yellen, G. (1991). Tetraethylammonium blockade distinguishes two inactivation mechanisms in voltageactivated $\mathrm{K}^{+}$channels. Proc. Natl. Acad. Sci. U.S.A. 88, 5092-5095.

Choi, W. S., Khurana, A., Mathur, R., Viswanathan, V., Steele, D. F., and Fedida, D. (2005). Kv1.5 surface expression is modulated by retrograde trafficking of newly endocytosed channels by the dynein motor. Circ. Res. 97, 363-371.

Choveau, F. S., Rodriguez, N., Ali, F. A., Labro, A. J., Rose, T., Dahimene, S., Boudin, H., Le Henaff, C., Escande, D., Snyders, D. J., Charpentier, F., Merot, J., Baro, I., and Loussouarn, G. (2011). KCNQ1 channels voltage dependency through a voltagedependent binding of the S4-S5 linker to the pore domain. J. Biol. Chem. 286, 707-716.

Clarke, O. B., Caputo, A. T., Hill, A. P., Vandenberg, J. I., Smith, B. J., and Gulbis, J. M. (2010). Domain reorientation and rotation of an intracellular assembly regulate conduction in Kir potassium channels. Cell 141, 1018-1029.

Cockerill, S. L., Tobin, A. B., Torrecilla, I., Willars, G. B., Standen, N. B., and Mitcheson, J. S. (2007). Modulation of hERG potassium currents in HEK-293 cells by protein kinase C. Evidence for direct phosphorylation of pore forming subunits. J. Physiol. 581, 479-493.

Coetze, W. A., Amarillo, Y., Chiu, J., Chow, A., Lau, D., McCormack, T., Moreno, H., Nadal, M. S., Ozaita, A., Poutney, D., Saganich, M., VegaSaenz de Miera, E., and Rudy, B. (1999). Molecular diversity of $\mathrm{K}^{+}$ channels. Ann. N. Y. Acad. Sci. 868, 233-2865.

Cohen, P. (2001). The role of protein phosphorylation in human health and disease. Eur. J. Biochem. 268, 5001-5010.
Covarrubias, M., Wei, A., Salkoff, L., and Vyas, T. B. (1994). Elimination of rapid potassium channel inactivation by phosphorylation of the inactivation gate. Neuron 13, 1403-1412.

Cox, D. H., and Hoshi, T. (2011). Where's the gate? Gating in the deep pore of the BKCa channel. J. Gen. Physiol. 238, 133-136.

Cuello, L. G., Joginin, V., Cortes, D. M., Pan, A. C., Gagnon, D. G., Dalmas, O., Cordero-Morales, J. F., Chakrapani, S., Roux, B., and Perozo, E. (2010). Structural basis for the coupling between activation and inactivation gates in $\mathrm{K}^{+}$channels. Nature 466, 272-275.

Cui, J., Kagan, A., Qin, D., Mathew, J., Melman, Y., and McDonald, T. V. (2001). Analysis of the cyclic nucleotide binding domain on the HERG potassium channel and interactions with KCNE2. J. Biol. Chem. 276, 17244-17251.

Cui, J., Melman, Y. F., Palma, E., Fishman, G. I., and McDonald, T. V. (2000). Cyclic AMP regulates the HERG $\mathrm{K}^{+}$channel by dual pathways. Curr. Biol. 10, 671-674.

Cukovic, D., Lu, G. W., Wible, B., Steele, D. F., and Fedida, D. (2001). A discrete amino terminal domain of Kv1.5 and Kv1.4 potassium channels interacts with the spectrin repeats of alpha-actinin-2. FEBS Lett. 498, 87-92.

Cushman, S. J., Nanao, M. H., Jahng, A. W., DeRubeis, D., Choe, S., and Pfaffinger, P. J. (2000). Voltage dependent activation of potassium channels is coupled to T1 domain structure. Nat. Struct. Biol. 7, 403-407.

De la Peña, P., Alonso-Ron, C., Machín, A., Fernández-Trillo, J., Carretero, L., Domínguez, P., and Barros, F. (2011). Demonstration of physical proximity between the amino terminus and the S4-S5 linker of the hERG potassium channel. J. Biol. Chem. 286, 19065-19075.

Decher, N., Chen, J., and Sanguinetti, M. C. (2004). Voltage-dependent gating of hyperpolarization-activated, cyclic nucleotide-gated pacemaker channels. molecular coupling between the S4-S5 and C-linkers. J. Biol. Chem. 279, 13859-13865.

del Camino, D., Holmgren, M., Liu, Y., and Yellen, G. (2000). Blocker protection in the pore of a voltagegated $\mathrm{K}^{+}$channel and its structural implications. Nature 403, 321-325.

del Camino, D., and Yellen, G. (2001). Tight steric closure of the intracellular activation gate of a voltage-gated $\mathrm{K}^{+}$channel. Neuron 32, 649-656.
Delgado, L. M., de la Peña, P. del Camino, D., and Barros, F. (1992). Okadaic acid and calyculin A enhance the effect of thyrotropinreleasing hormone on $\mathrm{GH} 3$ rat anterior pituitary cells excitability. FEBS Lett. 311, 41-45.

Demo, S. D., and Yellen, G. (1991). The inactivation gate of the Shaker $\mathrm{K}^{+}$channel behaves like an openchannel blocker. Neuron 7, 743-753.

Ding, S., and Horn, R. (2003). Effect of S6 tail mutations on charge movement in Shaker potassium channels. Biophys. J. 84, 295-305.

Drain, P., Dubin, A. E., and Aldrich, R. W. (1994). Regulation of Shaker $K^{+}$ channel inactivation gating by the cAMP-dependent protein kinase. Neuron 12, 1097-1109.

Emmi, A., Wenzel, H. J., Schwartzkroin, P. A., Taglialatela, M., Castaldo, P., Bianchi, L., Nerbonne, J., Robertson, G. A., and Janigro, D. (2000). Do glia have heart? Expression and functional role for ether-a-go-go currents in hippocampal astrocytes. $J$. Neurosci. 20, 3915-3925.

Etxeberria, A., Aivar, P., RodriguezAlfaro, J. A., Alaimo, A., Villacé, P., Gómez-Posada, J. C., Areso, P., and Villarroel, A. (2007). Calmodulin regulates the trafficking of KCNQ2 potassium channels. FASEB J. 22, 1135-1143.

Fan, Z., Ji, X., Zhang, D., and Xiao, Z. (2012). Electrostatic interaction between inactivation ball and T1S1 linker region of Kv1.4 channel. Biochim. Biophys. Acta 1818, 55-63.

Felipe, A., Vicente, R., Villalonga, N., Roura-Ferrer, M., MartínezMármol, R., Solé, L., Ferreres, J. C., and Condom, E. (2006). Potassium channels: new targets in cancer therapy. Cancer Detect. Prev. 30, 375-385.

Fernández-Trillo, J., Barros, F., Machín, A., Carretero, L., Domínguez, P., and de la Peña, P. (2011). Molecular determinants of interactions between the $\mathrm{N}$-terminal domain and the transmembrane core that modulate hERG $\mathrm{K}^{+}$channel gating. PLoS ONE 6, e24674. doi:10.1371/journal.pone. 0024674

Ferrer, T., Rupp, J., Piper, D. R., and Tristani-Firouzi, M. (2006). The S4-S5 linker directly couples voltage sensor movement to the activation gate in the human ether-a-go-go-related gene (hERG) $\mathrm{K}^{+}$channel. J. Biol. Chem. 281, 12858-12864.

Finlayson, K., Witchel, H. J., McCulloch, J., and Sharkey, J. (2004). Acquired QT interval prolongation and HERG: implications for drug discovery and development. Eur. J. Pharmacol. 500, 129-142.

Gamper, N., Li, Y., and Shapiro, M. S. (2005). Structural requirements for differential sensitivity of KCNQ $\mathrm{K}^{+}$channels to modulation by $\mathrm{Ca}^{2+} /$ calmodulin. Mol. Biol. Cell 16, 3538-3551.

Gamper, N., and Shapiro, M. S. (2003). Calmodulin mediates $\mathrm{Ca}^{2+}$. dependent modulation of M-type $\mathrm{K}^{+}$channels. J. Gen. Physiol. 122, 17-31.

Gamper, N., and Shapiro, M. S. (2007). Regulation of ion transport proteins by membrane phosphoinositides. Nat. Rev. Neurosci. 8, 921-934.

Gaudet, R. (2009). Divide and conquer: high resolution structural information on TRP channel fragments. J. Gen. Physiol. 133, 231-237.

Gebauer, M., Isbrandt, D., Sauter K., Callsen, B., and Nolting, A. (2004). N-type inactivation features of Kv2.4 channel gating. Biophys. J. 86, 210-223.

Ghosh, S., Nunziato, D. A., and Pitt, G. S. (2006). KCNQ1 assembly and function is blocked by long-QT syndrome mutations that disrupt interaction with calmodulin. Circ. Res. 98, 1048-1054.

Goldenberg, I., and Moss, A. J. (2008). Long QT syndrome. J. Am. Coll. Cardiol. 51, 2291-2300.

Gómez-Varela, D., Barros, F., Viloria, C. G., Giráldez, T., Manso, D. G., Dupuy, S. G., Miranda, P., and de la Peña, P. (2003). Relevance of the proximal domain in the aminoterminus of HERG channels for regulation by a phospholipase Ccoupled hormone receptor. FEBS Lett. 535, 125-130.

Gómez-Varela, D., de la Peña, P., García, J., Giráldez, T., and Barros, F. (2002). Influence of amino-terminal structures on kinetic transitions between several closed and open states in human erg $\mathrm{K}^{+}$channels. J. Membr. Biol. 187, 117-133.

Gonzalez, C., Lopez-Rodriguez, A., Srikumar, D., Rosenthal, J. J. C., and Holmgren, M. (2011). Editing of human Kv1.1 channel mRNAs disrupts binding of the $\mathrm{N}$-terminus tip at the intracellular cavity. Nat. Commun. 2:436. doi:10.1038/ncomms1446

Grabe, M., Lai, H. C., Jain, M., Jan, Y. N., and Jan, L. Y. (2007). Structure prediction for the down state of a potassium channel voltage sensor. Nature 445, 550-553.

Gulbis, J. M., Zhou, M., Mann, S., and MacKinnon, R. (2000). Structure of 
the cytoplasmic $\beta$ subunit-T1 assembly of voltage-dependent $\mathrm{K}^{+}$channels. Science 289, 123-127.

Gustina, A. S., and Trudeau, M. C. (2009). A recombinant $\mathrm{N}$-terminal domain fully restores deactivation gating in $\mathrm{N}$-truncated and long QT syndrome mutant $\mathrm{hERG}$ potassium channels. Proc. Natl. Acad. Sci. U.S.A. 106, 13082-13087.

Gustina, A. S., and Trudeau, M. C. (2011). hERG potassium channel gating is mediated by $\mathrm{N}$ - and $\mathrm{C}$ terminal region interactions. J. Gen. Physiol. 137, 315-325.

Gutman, G. A., Chandy, K. G., Grissmer, S., Lazdunski, M., McKinnon, D., Pardo, L. A., Robertson, G. A., Rudy, B., Sanguinetti, M. C., Stühmer, W., and Wang, X. (2005). International Union of Pharmacology. LIII. Nomenclature and molecular relationships of voltage-gated potassium channels. Pharmacol. Rev. 57, 473-508.

Hackos, D. A., Chang, T.-H., and Swartz, K. J. (2002). Scanning the intracellular S6 activation gate in the Shaker $\mathrm{K}^{+}$channel. J. Gen. Physiol. 119, 521-532.

Haitin, Y., and Attali, B. (2008). The C-terminus of Kv7 channels: a multifunctional module. J. Physiol. 586, 1803-1810.

Haitin, Y., Wiener, R., Shaham, D., Peretz, A., Cohen, E. B., Shamgar, L., Pongs, O., Hirsch, J. A., and Attali, B. (2009). Intracellular domains interactions and gated motions of IKS potassium channel subunits. $E M B O$ J. 28, 1994-2005.

Hatano, N., Ohya, S., Muraki, K., Clark, R. B., Giles, W. R., and Imaizumi, Y. (2004). Two arginines in the cytoplasmic C-terminal domain are essential for voltage-dependent regulation of A-type $\mathrm{K}^{+}$current in the $\mathrm{Kv} 4$ channel subfamily. J. Biol. Chem. 279, 5450-5459.

He, Y., Kang, Y., Leung, Y., Xia, F., Gao, X., Xie, H., Gaisano, H. Y., and Tsushima, R. G. (2006). Modulation of Kv2.1 channel gating and TEA sensitivity by distinct domains of SNAP-25. Biochem. J. 396, 363-369.

Hernandez, C. C., Zaika, O., Tolstykh, G. P., and Shapiro, M. S. (2008). Regulation of neural KCNQ channels: signalling pathways, structural motifs and functional implications. J. Physiol. 586, 1811-1821.

Hille, B. (1992). Ionic Channels of Excitable Membranes. Sunderland, MA: Sinauer.

Höllerer-Beitz, G., Schönherr, R., Koenen, M., and Heinemann, S. H. (1999). N-terminal deletions of rKv1.4 channels affect the voltage dependence of channel availability. Pflügers Arch. 438, 141-146.

Holmgren, M., Jurman, M. E., and Yellen, G. (1996). N-type inactivation and the S4-S5 region of the Shaker channel. J. Gen. Physiol. 108, 195-206.

Holmgren, M., Shin, K. S., and Yellen, G. (1998). The activation gate of a voltage-gated $\mathrm{K}^{+}$channel can be trapped in the open state by an intersubunit metal bridge. Neuron 21, 617-621.

Holmgren, M., Smith, P. L., and Yellen, G. (1997). Trapping of organic blockers by closing of voltagedependent $\mathrm{K}^{+}$channels: evidence for a trap door mechanism of activation gating. J. Gen. Physiol. 109, 527-535.

Hopkins, W. F., Demas, V., and Tempel, B. L. (1994). Both N- and C-terminal regions contribute to the assembly and functional expression of homo- and heteromultimeric voltage-gated $\mathrm{K}^{+}$channels. J. Neurosci. 14, 1385-1393.

Hoshi, T., Zagotta, W. N., and Aldrich, R. W. (1990). Biophysical and molecular mechanisms of Shaker potassium channel inactivation. Science 250, 533-538.

Howard, R. J., Clark, K., Holton, J. M., and Minor, D. L. Jr. (2007). Structural insight into KCNQ (Kv7) channel assembly and channelopathy. Neuron 53, 663-675.

Huang, X.-Y., Morielli, A. D., and Peralta, E. G. (1993). Tyrosine kinasedependent suppression of a potassium channel by the $G$ proteincoupled $\mathrm{m} 1$ muscarinic acetylcholine receptor. Cell 75, 1145-1156.

Isacoff, E. Y., Jan, Y. N., and Jan, L. Y. (1991). Putative receptor for the cytoplasmic inactivation gate in the Shaker $\mathrm{K}^{+}$channel. Nature 353, 86-90.

Jern, H. H., and Covarrubias, M. (1997). $\mathrm{K}^{+}$channel inactivation mediated $\mathrm{b}$ the concerted action of the cytoplasmic N- and C-terminal domains. Biophys. J. 72, 163-174.

Jian, Y., Lee, A., Chen, J., Ruta, V., Cadene, M., Chait, B. T., and MacKinnon, R. (2003). X-ray structure of a voltage-dependent $\mathrm{K}^{+}$channel. Nature 423, 33-41.

Jing, J., Peretz, T., Singer-Lahat, D., Chikvashvili, D., Thornhill, W. B., and Lotan, I. (1997). Inactivation of a voltage-dependent $\mathrm{K}^{+}$ channel by $\beta$ subunit: modulation by a phosphorylation-dependent interaction between the distal C terminus of $\alpha$ subunit and cytoskeleton. J. Bio. Chem. 272, 14021-14024.
Jonas, E. A., and Kaczmarek, L. K. (1996). Regulation of potassium channels by protein kinases. Curr. Opin. Neurobiol. 6, 318-323.

Ju, M., Stevens, L., Leadbitter, E., and Wray, D. (2003). The roles of $\mathrm{N}$ - and C-terminal determinants in the activation of the Kv2.1 potassium channel. J. Biol. Chem. 278, 12769-12778.

Kagan, A., Melman, Y., Krumerman, A., and McDonald, T. V. (2002). 14-33 amplifies and prolongs adrenergic stimulation of HERG $\mathrm{K}^{+}$channel activity. EMBO J. 21, 1889-1898.

Karle, C. A., Zitron, E., Zhang, W., Kathöfer, S., Schoels, W., and Kiehn, J. (2002). Rapid component IKr of the guinea-pig cardiac delayed rectifier $\mathrm{K}^{+}$current is inhibited by beta1adrenoreceptor activation, via protein kinase A-dependent pathways. Cardiovasc. Res. 53, 355-362.

Kass, R. S., Kurokawa, J., Marx, S. O., and Marks, A. R. (2003). Leucine/isoleucine zipper coordination of ion channel macromolecular signaling complexes in the heart: roles in inherited arrhythmias. Trends Cardiovasc. Med. 13, 52-56.

Keating, M. T., and Sanguinetti, M. C. (2001). Molecular and cellular mechanisms of cardiac arrhythmias. Cell 104, 569-580.

Kiehn, J. (2000). Regulation of the cardiac repolarizing HERG potassium channel by protein kinase A. Trends Cardiovasc. Med. 10, 205-209.

Kim, L. A., Furat, J., Gutierrez, D. Butler, M. H., Xu, S., Golstein, S. A. N., and Grigorieff, N. (2004). Three-dimensional structure of Ito: Kv4.2-KChIP2 ion channels by electron microscopy at $21 \AA$ resolution. Neuron 41, 513-519.

Kirchberger, N. M., Wulfsen, I., Schwarz, J. R., and Bauer, C. K. (2006). Effects of TRH on heteromeric rat ergla/lb $\mathrm{K}^{+}$channels are dominated by the rerg $1 \mathrm{~b}$ subunit. J. Physiol. 571, 27-42.

Kobertz, W. R., Williams, C., and Miller, C. (2000). Hanging gondola structure of the $\mathrm{T} 1$ domain in a voltagegated $\mathrm{K}^{+}$channel. Biochemistry 39 , 10347-10352

Kobrinsky, E., Stevens, L., Kazmi, Y., and Soldatov, N. M. (2006). Molecular rearrangements of the Kv2.1 potassium channel termini associated with voltage gating. J. Biol. Chem. 281, 19233-19240.

Kolbe, K., Schönherr, R., Gessner, G., Sahoo, N., Hoshi, T., and Heinemann, S. H. (2010). Cysteine 723 in the C-linker segment confers oxidative inhibition of hERG1 potassium channels. J. Physiol. 588 2999-3009.
Kondoh, S., Ishii, K., Nakamura, Y., and Taira, N. (1997). A mammalian transient type $\mathrm{K}^{+}$channel, rat Kv1.4, has two potential domains that could produce rapid inactivation. J. Biol. Chem. 272, 19333-19338.

Kreusch, A., Pfaffinger, P. J., Stevens, C. F., and Choe, S. (1998). Crystal structure of the tetramerization domain of the Shaker potassium channel. Nature 392, 945-948.

Kunjilwar, K., Strang, C., DeRubeis, D., and Pfaffinger, P. J. (2004). KChIP3 rescues the functional expression of Shal channel tetramerization mutants. J. Biol. Chem. 279, 54542-54551.

Kupershmidt, S., Snyders, D. J., Raes, A., and Roden, D. M. (1998). A $\mathrm{K}^{+}$channel splice variant common in human heart lacks a C-terminal domain required for expression of rapidly activating delayed rectifier current. J. Biol. Chem. 273, 27231-27235.

Labro, A. J., Boulet, I. R., Choveau, F., Mayeur, E., Bruyns, T., Loussouarn G., Raes, A. L., and Snyders, D. J. (2011). The S4-S5 linker of KCNQ1 channels forms a structural scaffold with the $\mathrm{S} 6$ segment controlling gate closure. J. Biol. Chem. 286, 717-725.

Labro, A. J., Raes, A. L., Grottesi, A., Van Hoorick, D., Sansom, M. S. P., and Snyders, D. J. (2008) $\mathrm{Kv}$ channel gating requires a compatible S4-S5 linker and bottom part of S6, constrained by noninteracting residues. J. Gen. Physiol. 132, 667-680.

Latorre, R., Olcese, R., Basso, C., Gonzalez, C., Muñoz, F., Cosmelli, D., and Alvarez, O. (2003). Molecular coupling between voltage sensor and pore opening in the Arabidopsis inward rectifier $\mathrm{K}^{+}$channel. J. Gen. Physiol. 122, 459-469.

Leung, Y. M., Kang, Y., Gao, X., Xia, F., Xie, H., Sheu, L., Tsuk, S., Lotan, I., Tsushima, R. G., and Gaisano, H. Y. (2003). Syntaxin 1A binds to the cytoplasmic C terminus of Kv2.1 to regulate channel gating and trafficking. J. Biol. Chem. 278, 17532-17538

Levitan, I. B. (1994). Modulation of ion channels by protein phosphorylation and de phosphorylation. Annu. Rev. Physiol. 56, 193-212.

Li, L., Liu, K., Hu, Y., Li, D., and Luan, S. (2008). Single mutations convert an outward $\mathrm{K}^{+}$channel into an inward $\mathrm{K}^{+}$channel. Proc. Natl. Acad. Sci. U.S.A. 105, 2871-2876.

Li, Q., Gayen, S., Chen, A. S., Huang, Q., Raida, M., and Kang, C. (2010). NMR solution structure of the Nterminal domain of hERG and its interaction with the S4-S5 linker. 
Biochem. Biophys. Res. Commun. 403, 126-132.

Li, Y., Liu, X., Wu, Y., Xu, Z., Li, H., Griffith, L. C., and Zhou, Y. (2011). Intracellular regions of the eag potassium channel play a critical role in generation of voltage-dependent currents. J. Biol. Chem. 286, 1389-1399.

Li, Y., Um, S. Y., and McDonald, T. V. (2006). Voltage-gated potassium channels: regulation by accessory subunits. Neuroscientist. 12, 199-210.

Liu, J., Zhang, M., Jiang, M., and Tseng, G.-N. (2003). Negative charges in the transmembrane domains of the HERG $\mathrm{K}$ channel are involved in the activation and deactivation gating processes. J. Gen. Physiol. 121, 599-614.

Liu, Y., Holmgren, M., Jurman, M. E., and Yellen, G. (1997). Gated access to the pore of a voltage-gated $\mathrm{K}^{+}$ channel. Neuron 19, 175-184.

Long, S. B., Campbell, E. B., and MacKinnon, R. (2005a). Crystal structure of a mammalian voltage-dependent Shaker family $\mathrm{K}^{+}$channel. Science 309, 897-902.

Long, S. B., Campbell, E. B., and Mackinnon, R. (2005b). Voltage sensor of Kv1.2: structural basis of electromechanical coupling. Science 309, 903-908.

Long, S. B., Tao, X., Campbell, E. B., and MacKinnon, R. (2007). Atomic structure of a voltage-dependent $\mathrm{K}^{+}$ channel in a lipid membrane-like environment. Nature 450, 376-382.

Lörinczi, E., Napp, J., Contreras-Jurado, C., Pardo, L. A., and Stühmer, W. (2009). The voltage dependence of hEag currents is not determined solely by membranespanning domains. Eur. Biophys. J. 38, 279-284.

Loussouarn, G., Park, K.-H., Bellocq, C., Baró, I., Charpentier, F., and Escande, D. (2003). Phosphatidylinositol 4,5-bisphosphate, PIP2, controls KCNQ1/KCNE1 voltage-gated potassium channels: a functional homology between voltage-gated and inward rectifier $\mathrm{K}^{+}$channels. EMBO J. 22, 5412-5421.

Lu, Y., Mahaut-Smith, M. P., Varghese, A., Huang, C. L., Kemp, P. R., and Vandenberg, J. I. (2001). Effects of premature stimulation on HERG $\mathrm{K}^{+}$ channels. J. Physiol. 537, 843-851.

Lu, Z., Klem, A. M., and Ramu, Y. (2002). Coupling between voltage sensors and activation gate in voltage-gated $\mathrm{K}^{+}$channels. J. Gen. Physiol. 120, 663-676.

Lvov, A., Greitzer, D., Berlin, S., Chikvashvili, D., Tsuk, S., and Lotan, I. (2009). Rearrangements in the relative orientation of cytoplasmic domains induced by a membraneanchored protein mediate modulations in $\mathrm{Kv}$ channel gating. J. Biol. Chem. 284, 28276-28291.

Maljevic, S., Wuttke, T. V., Seebohm, G., and Lerche, H. (2010). Kava7 channelopathies. Pflügers Arch. 460, 277-288.

Männikkö, R., Elinder, F., and Larsson, H. P. (2002). Voltage-sensing mechanism is conserved among ion channels gated by opposite voltages. Nature 419, 837-841.

Marten, I., and Hoshi, T. (1997). Voltage-dependent gating characteristics of the $\mathrm{K}^{+}$channel KAT1 depend on the $\mathrm{N}$ and $\mathrm{C}$ termini. Proc. Natl. Acad. Sci. U.S.A. 94, 3448-3453.

Marten, I., and Hoshi, T. (1998). The $\mathrm{N}$-terminus of the K channel KAT1 controls its voltage-dependent gating by altering the membrane electric field. Biophys. J. 74, 2953-2962.

Marx, S. O., Kurokawa, J., Reiken, S., Motoike, H., D’Armiento, J., Marks, A. R., and Kass, R. S. (2002). Requirement of a macromolecular signaling complex for b-adrenergic receptor modulation of the KCNQ1KCNE1 potassium channel. Science 295, 496-499.

Michaelevski, I., Chikvashvili, D., Tsuk, S., Fili, O., Lohse, M. J., Singer-Lahat, D., and Lotan, I. (2002). Modulation of a brain voltage-gated $\mathrm{K}^{+}$channel by syntaxin $1 \mathrm{~A}$ requires the physical interaction of $G \beta \gamma$ with the channel. J. Biol. Chem. 277, 34909-34917.

Minor, D. L. Jr. (2001). Potassium channels: life in the post-structural world. Curr. Opin. Struct. Biol. 11, 408-414.

Minor, D. L., Lin, Y.-F., Mobley, B. C., Avelar, A., Jan, Y. N., Jan, L. Y., and Berger, J. M. (2000). The polar $\mathrm{T} 1$ interface is linked to conformational changes that open the voltagegated potassium channel. Cell 102, 657-670.

Miranda, P., Giráldez, T., de la Peña, P., Manso, D. G., Alonso-Ron, C., Gómez-Varela, D., Domínguez, P., and Barros, F. (2005). Specificity of $\mathrm{TRH}$ receptor coupling to $\mathrm{G}$ proteins for regulation of $\mathrm{ERG}^{+}$ channels in GH3 rat anterior pituitary cells. J. Physiol. 566, 717-736.

Miranda, P., Manso, D. G., Barros, F., Carretero, L., Hughes, T. E., Alonso-Ron, C., Domínguez, P., and de la Peña, P. (2008). FRET with multiply labeled HERG $\mathrm{K}^{+}$channels as a reporter of the in vivo coarse architecture of the cytoplasmic domains. Biochim. Biophys. Acta 1783, 1681-1699.
Mohapatra, D. P., Siino, D. F., and Trimmer, J. S. (2008). Interdomain cytoplasmic interactions govern the intracellular trafficking, gating, and modulation of the Kv2.1 channel. $J$. Neurosci. 28, 4982-4994.

Mohapatra, D. P., and Trimmer, J. S. (2006). The Kv2.1 C terminus can autonomously transfer Kv2.1-like phosphorylation-dependent localization, voltage-dependent gating, and muscarinic modulation to diverse Kv channels. J. Neurosci. 26, 685-695.

Morais-Cabral, J. H., Lee, A., Cohen, S. L., Chait, B. T., Li, M., and MacKinnon, R. (1998). Crystal structure and functional analysis of the HERG potassium channel $\mathrm{N}$ terminus: a eukaryotic PAS domain. Cell 95, 649-655.

Murakoshi, H., Shi, G., Scannevin, R. H., and Trimmer, J. S. (1997). Phosphorylation of the Kv2.1 channel alters voltage-dependent activation. Mol. Pharmacol. 52, 821-828.

Muskett, F. W., Thouta, S., Thomson, S. J., Bowen, A., Stansfeld, P. J., and Mitcheson, J. S. (2011). Mechanistic insight into hERG $\mathrm{K}^{+}$channel deactivation gating from the solution structure of the eag domain. J. Biol. Chem. 286, 6184-6191.

Ng, C. A., Hunter, M. J., Perry, M. D., Mobli, M., Ke, Y., Kuchel, P. W., King, G. F., Stock, D., and Vandenberg, J. I. (2011). The N-terminal tail of hERG contains an amphipathic $\alpha$-helix that regulates channel deactivation. PLOS ONE 6, e16191. doi:10.1371/journal.pone.0016191

Nishizawa, M., and Nishizawa, K. (2009). Coupling of S4 helix translocation and S6 gating analyzed by molecular-dynamics simulations and mutated Kv channels. Biophys. J. 97, 90-100.

Norton, R. S., and Gulbis, J. M. (2010). Potassium channel gating: not an open and shut case. Proc. Natl. Acad. Sci. U.S.A. 107, 7623-7624.

Orlova, E. V., Papakosta, M., Booy, F. P., Van Heel, M., and Dolly, J. O. (2003). Voltage-gated $\mathrm{K}^{+}$channel from mammalian brain: 3D structure at $18 \AA$ of the complete $(\alpha) 4(\beta) 4$ complex. J. Mol. Biol. 326, 1005-1012.

Overholt, J. L., Ficker, E., Yang, T., Shams, H., Bright, G. R., and Prabhakar, N. R. (2000). HERG-like potassium current regulates the resting membrane potential in glomus cells of the rabbit carotid body. $J$. Neurophysiol. 83, 1150-1157.

Parcej, D. N., and Eckhardt-Strelau, L. (2003). Structural characterisation of neuronal voltage-sensitive $\mathrm{K}^{+}$ channels heterologously expressed in Pichia pastoris. J. Mol. Biol. 333, 103-116.

Park, K. H., Piron, J., Dahimene, S., Merot, J., Baro, I., Escande, D., and Loussouarn, G. (2005). Impaired KCNQ1-KCNE1 and Phosphatidylinositol-4,5bisphosphate interaction underlies the long QT syndrome. Circ. Res. 96, 730-739.

Park, K.-S., Mohapatra, D. P., and Trimmer, J. S. (2007). Proteomic analysis of Kv2.1 channel phosphorylation sites determining cell background specific differences in function. Channels 1, 59-61.

Park, K.-S., Yang, J.-W., Seikel, E., and Trimmer, J. S. (2008). Potassium channel phosphorylation in excitable cells: providing dynamic functional variability to a diverse family of ion channels. Physiology 23, 49-57.

Pascual, J. M., Shieh, C.-C. Kirsch, G. E., and Brown, A. M. (1997). Contribution of the $\mathrm{NH} 2$ terminus of Kv2.1 to channel activation. Am. J. Physiol. 273, C1849-C1858.

Perozo, E., Cortes, D. M., and Cuello, L. G. (1999). Structural rearrangements underlying $\mathrm{K}^{+}$channel activation gating. Science 285, 73-78.

Pioletti, M., Findeisen, F., Hura, G. L., and Minor, D. L. Jr. (2006). Three-dimensional structure of the KchIP1-Kv4.3 T1 complex reveals a cross-shaped octamer. Nat. Struct. Mol. Biol. 13, 987-995.

Piper, D. R., Varghese, A., Sanguinetti, M. C., and Tristani-Firouzi, M. (2003). Gating currents associated with intramembrane charge displacement in HERG potassium channels. Proc. Natl. Acad. Sci. U.S.A. 100, 10534-10539.

Pischalnikova, A. V., and Sokolova, O. S. (2009). The domain and conformational organization in potassium voltage-gated ion channels. $J$. Neuroimmune Pharmacol. 4, 71-82.

Ponce, A., Vega-Saenz de Miera, E. Kentros, C., Moreno, H., Thornhill, B., and Rudy, B. (1997). $\mathrm{K}^{+}$channel subunit isoforms with divergent carboxy-terminal sequences carry distinct membrane targeting signals. J. Membr. Biol. 159, 149-159.

Pongs, O., and Schwarz, J. R. (2010). Ancillary subunits associated with voltage-dependent $\mathrm{K}^{+}$channels. Physiol. Rev. 90, 755-796.

Prole, D. L., and Yellen, G. (2006). Reversal of HCN channel voltage dependence via bridging of the S4-S5 linker and post-S6. J. Gen. Physiol. 128, 273-282. 
Rasmusson, R. L., Morales, M. J., Wang, S., Liu, S., Campbell, D. L., Brahmajothi, M. V., and Strauss, H. C. (1998). Inactivation of voltage-gated cardiac $\mathrm{K}^{+}$channels. Circ. Res. 82, 739-750.

Redfern, W. S., Carlsson, L., Davis, A. S., Lynch, W. G., MacKenzie, I., Palethorpe, S., Siegl, P. K. S., Strang, I., Sullivan, A. T., Wallis, R., Camm, A. J., and Hammond, T. G. (2002). Relationships between preclinical cardiac electrophysiology, clinical QT interval prolongation and torsade de pointes for a broad range of drugs: evidence for a provisional safety margin in drug development. Cardiovasc. Res. 58, 32-45.

Roden, D. M., and Viswanathan, P. C. (2005). Genetics of acquired long QT syndrome. J. Clin. Invest. 115, 2025-2032.

Roeper, J., Sewing, S., Zhang, Y., Sommer, T., Wanner, S. G., and Pongs, O. (1998). NIP domain prevents Ntype inactivation in voltage-gated potassium channels. Nature 391, 390-393.

Roosild, T. P., Le, K.-T., and Choe, S. (2004). Cytoplasmic gatekeepers of $\mathrm{K}^{+}$-channel flux: a structural perspective. Trends Biochem. Sci. 29, 39-45.

Rosati, B., Marchetti, P., Crociani, O., Lecchi, M., Lupi, R., Arcangeli, A., Olivotto, M., and Wanke, E. (2000). Glucose- and arginineinduced insulin secretion by human pancreatic $\beta$-cells: the role of HERG $\mathrm{K}^{+}$channels in firing and release. FASEB J. 14, 2601-2610.

Ruppersberg, J. P., Frank, R., Pongs, O., and Stocker, M. (1991). Cloned neuronal IK(A) channels reopen during recovery from inactivation. Nature 353, 657-660.

Saenen, J. B., Labro, A. J., Raes, A., and Snyders, D. J. (2006). Modulation of HERG gating by a charge cluster in the N-terminal proximal domain. Biophys. J. 91, 4381-4391.

Sanguinetti, M. C, Jiang, C, Curran, M. E., and Keating, M. T. (1995). A mechanistic link between an inherited and an acquired cardiac arrhythmia. Cell 81, 299-307.

Sankaranarayanan, K., Varshney, A., and Mathew, M. K. (2005). N type rapid inactivation in human Kv1.4 channels: functional role of a putative C-terminal helx. Mol. Membr. Biol. 22, 389-400.

Scannevin, R. H., Wang, K., Jow, F., Megules, J., Kopsco, D. C., Edris, W., Carroll, K. C., Lü, Q., Xu, W., Xu, Z., Katz, A. H., Olland, S., Lin, L., Taylor, M., Stahl, M., Malakian, K.,
Somers, W., Mosyak, L., Bowlby, M. R., Chanda, P., and Rhodes, K. J. (2004). Two N-terminal domains of $\mathrm{Kv} 4 \mathrm{~K}^{+}$channels regulate binding to and modulation by KchIP1. Neuron 41, 587-598.

Schäfer, R., Wulfsen, I., Behrens, S., Weinsberg, F., Bauer, C. K., and Schwarz, J. R. (1999). The erg-like current in rat lactotrophs. J. Physiol. 518, 401-416.

Scholle, A., Zimmer, T., Koopmann, R., Engeland, B., Pongs, O., and Benndorf, K. (2004). Effects of Kv1.2 intracellular regions on activation of Kv2.1 channels. Biophys. J. 87, 873-882.

Schönherr, R., and Heinemann, S. H. (1996). Molecular determinants for activation and inactivation of HERG, a human inward rectifier potassium channel. J. Physiol. 493, 635-642.

Schott, M. K., Antz, C., Frank, R., Ruppersberg, J. P., and Kalbitzer, H. R. (1998). Structure of the inactivation gate from the Shaler voltagegated $\mathrm{K}^{+}$channel analyzed by NMR spectroscopy. Eur. Biophys. J. 27, 99-104.

Schrader, L. A., Ren, Y., Cheng, F., Bui, D., Sweatt, J. D., and Anderson, A. E. (2009). Kv4.2 is a locus for PKC and ERK/MAPK cross-talk. Biochem. J. 417, 705-715.

Schulteis, C. T., Nagaya, N., and Papazian, D. M. (1998). Subunit folding and assembly steps are interspersed during Shaker potassium channel biogenesis. J. Biol. Chem. 273, 26210-26217.

Schünke, S., Stoldt, M., Lecher, J., Kaupp, U. B., and Willbold, D. (2011). Structural insights into conformational changes of a cyclic nucleotide-binding domain in solution from Mesorhizobium loti K1 channel. Proc. Natl. Acad. Sci. U.S.A. 108, 6121-6126.

Sentenac, H., Bonneaud, N., Minet, M., Lacroute, F., Salmon, J. M., Gaymard, F., and Grignon, C. (1992). Cloning and expression in yeast of a plant potassium ion transport system. Science 256, 663-665.

Shahidullah, M., Santarelli, L. C., Wen, H., and Levitan, I. B. (2005). Expression of a calmodulinbinding KCNQ2 potassium channel fragment modulates neuronal $\mathrm{M}$ current and membrane excitability. Proc. Natl. Acad. Sci. U.S.A. 102 16454-16459.

Shamgar, L., Ma, L., Schmitt, N., Haitin, Y., Peretz, A., Wiener, R., Hirsch, J., Pongs, O., and Atali, B. (2006). Calmodulin is essential for cardiac IKS channel gating and assembly: impaired function in long-QT mutations. Circ. Res. 98, 1055-1063.

Smith, P. L., Baukrowitz, T., and Yellen, G. (1996). The inward rectification mechanism of the HERG cardiac potassium channel. Nature 379, 833-836.

Smith, P. L., and Yellen, G. (2002). Fast and slow voltage sensor movements in HERG potassium channels. J. Gen. Physiol. 119, 275-293.

Sokolova, O., Accardi, A., Gutierrez, D., Lau, A., Rigney, M., and Grigorieff, N. (2003). Conformational changes in the $\mathrm{C}$ terminus of Shaker $\mathrm{K}^{+}$ channel bound to the rat $\operatorname{Kv} \beta 2$ subunit. Proc. Natl. Acad. Sci. U.S.A. 100, 12607-12612.

Sokolova, O., Kolmakova-Partensky, L. and Grigorieff, N. (2001). Threedimensional structure of a voltagegated potassium channel at $2.5 \mathrm{~nm}$ resolution. Structure 9, 215-220.

Spector, P. S., Curran, M. E., Zou, A., Keating, M. T., and Sanguinetti, M. C. (1996). Fast inactivation causes rectification of the $\mathrm{IKr}$ channel. $J$. Gen. Physiol. 107, 611-619.

Stevens, L., Ju, M., and Wray, D. (2009). Roles of surface residues of intracellular domains of heag potassium channels. Eur. Biophys. J. 38 523-532.

Subbiah, R. N., Clarke, C. E., Smith, D. J., Zhao, J., Campbell, T. J., and Vandenberg, J. I. (2004). Molecular basis of slow activation of the human ether-á-go-go related gene potassium channel. J. Physiol. 558, 417-431.

Subbiah, R. N., Kondo, M., Campbell, T. J., and Vandenberg, J. I. (2005). Tryptophan scanning mutagenesis of the HERG $\mathrm{K}^{+}$channel: the S4 domain is loosely packed and likely to be lipid exposed. J. Physiol. 569, 367-379.

Suh, B., and Hille, B. (2005). Regulation of ion channels by phosphatidylinositol 4,5-bisphosphate. Curr. Opin. Neurobiol. 15, 1-9.

Surti, T. S., Huang, L., Jan, Y. N., Jan, L. Y., and Cooper, E. C. (2005). Identification by mass spectrometry and functional characterization of two phosphorylation sites of KCNQ2/KCNQ3 channels. Proc. Natl. Acad. Sci. U.S.A. 102, 17828-17833.

Swartz, K. J. (2004). Towards a structural view of gating in potassium channels. Nat. Rev. Neurosci. 5, 905-916.

Swartz, K. J. (2008). Sensing voltage across lipid membranes. Nature 456, 891-897.

Taraska, J. W., and Zagotta, W. N. (2007). Structural dynamics in the gating ring of cyclic nucleotidegated ion channels. Nat. Struct. Mol. Biol. 14, 854-860.

Terlau, H., Heinemann, S. H., Stühmer, W., Pongs, O., and Ludwig, J. (1997). Amino terminal-dependent gating of the potassium channel rat eag is compensated by a mutation in the S4 segment. J. Physiol. 502, 537-543.

Thomas, D., Wu, K., Wimmer, A.B., Zitron, E., Hammerling, B. C., Kathöfer, S., Lueck, S., Bloehs, R., Kreye, V. A. W., Kiehn, J., Katus, H. A., Schoels, W., and Karle, C. A. (2004). Activation of cardiac human ether-a-go-go related gene potassium currents is regulated by $\alpha 1 \mathrm{~A}$ adrenoreceptors. J. Mol. Med. 82, 826-837.

Thomas, D., Zhang, W., Karle, C. A., Kathöfer, S., Schöls, W., Kübler, W., and Kiehn, J. (1999). Deletion of protein kinase A phosphorylation sites in the HERG potassium channel inhibits activation shift by protein kinase A. J. Biol. Chem. 274, 27457-27462.

Thomas, D., Zhang, W., Wu, K., Wimmer, A.-B., Gut, B., Wendt-Nordahl, G., Kathöfer, S., Kreye, V. A. W., Katus, H. A., Schoels, W., Kiehn, J., and Karle, C. A. (2003). Regulation of potassium channel activation by protein kinase $\mathrm{C}$ independent of direct phosphorylation of the channel protein. Cardiovasc. Res. 59, 14-26.

Tristani-Firouzi, M., Chen, J., and Sanguinetti, M. C. (2002). Interactions between S4-S5 linker and S6 transmembrane domain modulate gating of HERG K ${ }^{+}$channels. J. Biol. Chem. 277, 18994-19000.

Trudeau, M. C., Warmke, J. W., Ganetzky, B., and Robertson, G. A. (1995). HERG, a human inward rectifier in the voltage-gated potassium channel family. Science 269, 92-95.

Tsai, W., Morielli, A. D., Cachero, T. G., and Peralta, E. G. (1999). Receptor protein tyrosine phosphatase $\alpha$ participates in the $\mathrm{ml}$ muscarinic acetylcholine receptordependent regulation of Kv1.2 channel activity. $E M B O$ J. 18, 109-118.

Uysal, S., Cuello, L. G., Cortes, D. M., Koide, S., Kossiakoff, A. A., and Perozo, E. (2011). Mechanism of activation gating in the full-length KcsA $\mathrm{K}^{+}$channel. Proc. Natl. Acad. Sci. U.S.A. 108, 11896-11899.

Vacher, H., and Trimmer, J. S. (2011). Diverse roles for auxiliary subunits in phosphorylation-dependent regulation of mammalian brain voltage-gated potassium channels. Pflügers Arch. 462, 631-643. 
VanDongen, A. M. J., Frech, G. C., Drewe, J. A., Joho, R. H., and Brown, A. M. (1990). Alteration and restoration of $\mathrm{K}^{+}$channel function by deletions at the $\mathrm{N}$ - and $\mathrm{C}$-termini. Neuron 5, 433-443.

Varhsney, A., Chanda, B., and Mathew, M. K. (2004). Arranging the elements of the potassium channel: the T1 domain occludes the cytoplasmic face of the channel. Eur. Biophys. J. 33, 370-376.

Varshney, A., and Mathew, M. K. (2003). A tale of two tails: cytosolic termini and $\mathrm{K}^{+}$channel function. Prog. Biophys. Mol. Biol. 83, 153-170.

Vemana, S., Pandey, S., and Larsson, H. P. (2004). S4 movement in a mammalian HCN channel. J. Gen. Physiol. 123, 21-32.

Viloria, C. G., Barros, F., Giráldez, T., Gómez-Varela, D., and de la Peña, P. (2000). Differential effects of amino-terminal distal and proximal domains in the regulation of human erg $\mathrm{K}^{+}$channel gating. Biophys. J. 79, 231-246.

Viskin, S. (1999). Long QT syndromes and torsade de pointes. Lancet 354, 1625-1633.

Wang, D. T., Hill, A. P., Mann, S. A., Tan, P. S., and Vandenberg, J. I. (2011). Mapping the sequence of conformational changes underlying selectivity filter gating in the Kv11.1 potassium channel. Nat. Struct. Mol. Biol. 18, 35-41.

Wang, G., and Covarrubias, $M$. (2006). Voltage-dependent gating rearrangements in the intracellular T1-T1 interface of a $\mathrm{K}^{+}$channel. J. Gen. Physiol. 127, 391-400.

Wang, G., Shahidullah, M., Rocha, C. A., Strang, C., Pfaffinger, P. J., and Covarrubias, M. (2005). Functionally active $\mathrm{T} 1-\mathrm{T} 1$ interfaces revealed by the accessibility of intracellular thiolate groups in $\mathrm{Kv} 4$ channels. J. Gen. Physiol. 126, 55-69.

Wang, J., Myers, C. D., and Robertson, G. A. (2000). Dynamic control of deactivation gating by a soluble aminoterminal domain in HERG $\mathrm{K}^{+}$channels. Biophys. J. 115, 749-758.

Wang, J., Trudeau, M. C., Zappia, A. M., and Robertson, G. A. (1998). Regulation of deactivation by an amino terminal domain in human ether-a-gogo-related gene potassium channels. J. Gen. Physiol. 112, 637-647.
Wang, L., and Sigworth, F. J. (2009). Structure of the BK potassium channel in a lipid membrane from electron cryomicroscopy. Nature 461, 242-245.

Warmke, J. W., and Ganetzky, B. (1994). A family of potassium channel genes related to eag in Drosophila and mammals. Proc. Natl. Acad. Sci. U.S.A. 91, 3438-3442.

Webster, S. M., del Camino, D., Dekker, J. P., and Yellen, G. (2004). Intracellular gate opening in Shaker $\mathrm{K}^{+}$channels defined by high-affinity metal bridges. Nature 428, 864-868.

Wen, H., and Levitan, I. B. (2002). Calmodulin is an auxiliary subunit of KCNQ2/3 potassium channels. $J$. Neurosci. 22, 7991-8001.

Whang, Z., Wilson, G. F., and Griffith L. C. (2002). Calcium/calmodulindependent protein kinase II phosphorylates and regulates the Drosophila eag potassium channel. J. Biol. Chem. 277, 24022-24029.

Wiener, R., Haitin, Y., Shamgar, L., Fernández-Alonso, M. C., Martos, A., Chomsky-Hecht, O., Rivas, G., Attali, B., and Hirsch, J. A. (2008). The KCNQ1 (Kv7.1) COOH terminus, a multitiered scaffold for subunit assembly and protein interaction. J. Biol. Chem. 283, 5815-5830.

Wissmann, R., Bildl, W., Oliver, D., Beyermann, M., Kalbitzer, H. R., Bentrop, D., and Fakler, B. (2003). Solution structure and function of the "tandem inactivation domain" of the neuronal A-type potassium channel Kv1.4. J. Biol. Chem. 278, 16142-16150.

Wray, D. (2009). Intracellular regions of potassium channels: Kv2.1 and heag. Eur. Biophys. J. 38, 285-292.

Wulff, H., Castle, N. A., and Pardo, L. A. (2009). Voltage-gated potassium channels as therapeutic targets. Nat. Rev. Drug Disc. 8, 982-1001.

Wynia-Smith, S. L., Gillian-Daniel,A. L., Satyshur, K. A., and Robertson, G. A. (2008). hERG gating micro domains defined by $\mathrm{S} 6$ mutagenesis and molecular modeling. J. Gen. Physiol. 132, 507-520.

Xu, J., Yu, W., Jan, Y. N., Jan, L. Y., and Li, M. (1995). Assembly of voltage-gated potassium channels. Conserved hydrophilic motifs determine subfamily-specific interactions between the alpha-subunits. J. Biol. Chem. 270, 24761-24768.
$\mathrm{Xu}, \mathrm{M}$. , Gu, Y., Barry, J., and $\mathrm{Gu}$, C. (2010). Kinesin I transports tetramerized Kv3 channels through the axon initial segment via direct binding. J. Neurosci. 30 15987-16001.

Yang, E. K., Alvira, M. R., Levitan, E. S., and Takimoto, K. (2001). Kvbeta subunits increase expression of Kv4.3 channels by interacting with their C termini. J. Biol. Chem. 276, 4839-4844.

Yellen, G. (1998). The moving parts of voltage-gated ion channels. Q. Rev. Biophys. 31, 239-295.

Yellen, G. (2002). The voltage-gated potassium channels and their relatives. Nature 419, 35-42.

Yu, F. H., Yarov-Yarovoy, V., Gutman, G. A., and Catterall, W. A. (2005). Overview of molecular relationships in the voltage-gated ion channel superfamily. Pharmacol. Rev. 57, 387-395.

Yus-Nájera, E., Santana-Castro, I., and Villarroel, A. (2002). The identification and characterization of noncontinuous calmodulinbinding site in noninactivating voltage-dependent KCNQ potassium channels. J. Biol. Chem. 277, 28545-28553.

Zagotta, W. N., Hoshi, T., and Aldrich, R. W. (1990). Restoration of inactivation in mutants of Shaker $\mathrm{K}^{+}$ channels by a peptide derived from ShB. Science 250, 568-571.

Zagotta, W. N., Olivier, N. B., Black, K. D., Young, E. C., Olson, R., and Gouaux, E. (2003). Structural basis for modulation and agonist specificity of $\mathrm{HCN}$ pacemaker channels. Nature 425, 200-205.

Zhang, H., Craciun, L. C., Mirshahi, T., Rohács, T., Lopes, C. M. B., Jin, T., and Logothetis, D. E. (2003). PIP2 activates KCNQ channels, and its hydrolysis underlies receptormediated inhibition of $\mathrm{M}$ currents. Neuron 37, 963-975.

Zhang, M., Liu, J., Jiang, M., Wu, D.-M., Sonawane, K., Guy, H. R., and Tseng, G.-N. (2005). Interactions between charged residues in the transmembrane segments of the voltage-sensing domain in the hERG channel. J. Membr. Biol. 207, 169-181.

Zhang, M., Liu, J., and Tseng, G.-N. (2004). Gating charges in the activation and inactivation processes of the HERG channel. J. Gen. Physiol. 124, 703-718

Zhao, L.-L., Wu, A., Bi, L.-J., Liu, P., Zhang, X.-E., Jiang, T., Jin, G., and Qi, Z. (2009). Length-dependent regulation of the Kv1.2 channel activation by its C-terminus. Mol. Membr. Biol. 26, 186-193.

Zheng, R., Thompson, K., ObengGymah, E., Alessi, D., Chen, J., Cheng, H., and McDonald, T. V. (2010). Analysis of the interactions between the C-terminal cytoplasmic domains of KCNQ1 and KCNE1 channel subunits. Biochem. J. 428, 75-84.

Zhou, M., Morais-Cabral, J. H., Mann, S., and MacKinnon, R. (2001). Potassium channel receptor site for the inactivation gate and quaternary amine inhibitors. Nature 411, 657-661.

Zhou, W., and Jan, L. (2010). A twist on potassium channel gating. Cell 141, 920-922.

Ziechner, U., Schönherr, R., Born, A., Gavrilova-Ruch, O., Glaser, R. W., Malesevic, M., Küllertz, G., and Heinemann, S. H. (2006). Inhibition of human ether á go-go potassium channels by $\mathrm{Ca}^{2+} /$ calmodulin binding to the cytosolic $\mathrm{N}$ - and C-termini. FEBS J. 273, 1074-1086.

Conflict of Interest Statement: The authors declare that the research was conducted in the absence of any commercial or financial relationships that could be construed as a potential conflict of interest.

Received: 24 October 2011; accepted: 05 March 2012; published online: 23 March 2012.

Citation: Barros F, Domínguez $P$ and de la Peña P (2012) Cytoplasmic domains and voltage-dependent potassium channel gating. Front. Pharmacol. 3:49. doi: 10.3389/fphar.2012.00049

This article was submitted to Frontiers in Pharmacology of Ion Channels and Channelopathies, a specialty of Frontiers in Pharmacology.

Copyright (c) 2012 Barros, Domínguez and de la Peña. This is an open-access article distributed under the terms of the Creative Commons Attribution Non Commercial License, which permits noncommercial use, distribution, and reproduction in other forums, provided the original authors and source are credited. 